\title{
Dopaminergic Signaling in the Nucleus Accumbens Modulates Stress-Coping Strategies during Inescapable Stress
}

\author{
Wanpeng Cui, ${ }^{1,2,3}$ Tomomi Aida, ${ }^{2,4}$ Hikaru Ito, ${ }^{1}$ Kenta Kobayashi, ${ }^{5}$ Yusaku Wada, ${ }^{6}$ Shigeki Kato, ${ }^{7}$ \\ ${ }^{1}$ Takashi Nakano, ${ }^{1}$ Meina Zhu, ${ }^{1}$ Kaoru Isa, ${ }^{8}$ Kazuto Kobayashi, ${ }^{7}$ Tadashi Isa, ${ }^{8}$ Kohichi Tanaka, ${ }^{2}$ and \\ Hidenori Aizawa ${ }^{1,2}$ \\ ${ }^{1}$ Department of Neurobiology, Institute of Biomedical and Health Sciences, Hiroshima University, Hiroshima 734-8553, Japan, ${ }^{2}$ Laboratory of Molecular \\ Neuroscience, Medical Research Institute, Tokyo Medical and Dental University, Tokyo 113-8510, Japan, ${ }^{3}$ Department of Neurosciences, School of Medicine, \\ Case Western Reserve University, Cleveland, $\mathrm{OH} 44106,{ }^{4} \mathrm{McGovern}$ Institute for Brain Research, Department of Brain and Cognitive Sciences, Massachusetts \\ Institute of Technology, Cambridge, MA 02139, ${ }^{5}$ Section of Viral Vector Development, National Institute of Physiological Sciences, Okazaki, Aichi 444-8585, \\ Japan, ${ }^{6}$ FASMAC Company Ltd, Atsugi 243-0041, Japan, ${ }^{7}$ Department of Molecular Genetics, Institute of Biomedical Sciences, Fukushima Medical \\ University, Fukushima 960-1295, Japan, and ${ }^{8}$ Department of Neuroscience, Graduate School of Medicine, Kyoto University, Kyoto 606-8501, Japan
}

Maladaptation to stress is a critical risk factor in stress-related disorders, such as major depression and post-traumatic stress disorder (PTSD). Dopamine signaling in the nucleus accumbens (NAc) has been shown to modulate behavior by reinforcing learning and evading aversive stimuli, which are important for the survival of animals under environmental challenges such as stress. However, the mechanisms through which dopaminergic transmission responds to stressful events and subsequently regulates its downstream neuronal activity during stress remain unknown. To investigate how dopamine signaling modulates stress-coping behavior, we measured the subsecond fluctuation of extracellular dopamine concentration and $\mathrm{pH}$ using fast scanning cyclic voltammetry (FSCV) in the NAc, a postsynaptic target of midbrain dopaminergic neurons, in male mice engaged in a tail suspension test (TST). The results revealed a transient decrease in dopamine concentration and an increase in $\mathrm{pH}$ levels when the animals changed behaviors, from being immobile to struggling. Interestingly, optogenetic inhibition of dopamine release in NAc, potentiated the struggling behavior in animals under the TST. We then addressed the causal relationship of such a dopaminergic transmission with behavioral alterations by knocking out both the dopamine receptors, i.e., D1 and D2, in the NAc using viral vector-mediated genome editing. Behavioral analyses revealed that male D1 knock-out mice showed significantly more struggling bouts and longer struggling durations during the TST, while male D2 knock-out mice did not. Our results therefore indicate that D1 dopaminergic signaling in the NAc plays a pivotal role in the modulation of stress-coping behaviors in animals under tail suspension stress.

Key words: animals; depression; dopamine; genome editing; striatum; voltammetry

Significance Statement

The tail suspension test (TST) has been widely used as a despair-based behavioral assessment to screen the antidepressant so long. Despite its prevalence in the animal studies, the neural substrate underlying the changes of behavior during the test remains unclear. This study provides an evidence for a role of dopaminergic transmission in the modulation of stress-coping behavior during the TST, a despair test widely used to screen the antidepressants in rodents. Taking into consideration the fact that the dopamine metabolism is upregulated by almost all antidepressants, a part of which acts directly on the dopaminergic transmission, current results would uncover the molecular mechanism through which the dopaminergic signaling mediates antidepressant effect with facilitation of the recovery from the despair-like behavior in the TST.

Received Feb. 24, 2020; revised Aug. 10, 2020; accepted Aug. 16, 2020.

Author contributions: W.C. and H.A. designed research; W.C., T.A., H.I., Ke.K., Y.W., and H.A. performed research; W.C., T.A., Ke.K., S.K., K.I., Ka.K., T.I., K.T., and H.A. contributed unpublished reagents/analytic tools; W.C., T.A., H.I., T.N., M.Z., and H.A. analyzed data; W.C. and H.A. wrote the paper.

This work was supported by the Program of the Network-type Joint Usage/Research Center for Radiation Disaster Medical Science, Natural Science Center for Basic Research and Development, Hiroshima University, and funds were provided by the Kato Memorial Bioscience Foundation. This work was also supported by Grants-in-Aid for Scientific Research on Innovative Areas (KAKENHI26112010 and JP19H05723), a Grant-in-Aid for Challenging Exploratory Research (KAKENHI17K19459) from the Ministry of Education, Culture, Sports, Science, and Technology (MEXT), and a Grant-in-Aid for Integrated Research on Depression, Dementia and Development Disorders (20dm0107093h) carried out under the Strategic Research Program for Brain Sciences by Japan Agency for Medical Research and Development (AMED) (to H.A.).

The authors declare no competing financial interests.

Acknowledgments: We thank Dr. Michael Heien, Dr. Christopher Atcherley, and Dr. Mark Wightman for their technical advice on voltammetric analysis; Dr. Deepa Kamath Kasaragod for critical reading of the manuscript; and Ms. Fumie Nishimura and Harumi Ishikubo for their technical assistance.

Correspondence should be addressed to Hidenori Aizawa at haizawa@hiroshima-u.ac.jp.

https://doi.org/10.1523/JNEUROSCI.0444-20.2020

Copyright $\odot 2020$ the authors 


\section{Introduction}

Appropriate responses to stress are essential for an individual's survival and well-being. In psychiatric disorders such as major depression and post-traumatic stress disorder (PTSD), stresscoping strategies in patients are maladaptive, resulting in loss of motivation and exaggerated fear responses under stress (Segal et al., 1992). The mesolimbic dopaminergic pathway is a projection from the ventral tegmental area (VTA) to ventral striatal structures, such as the nucleus accumbens (NAc). The mesolimbic dopamine pathway is known for its role in incentive salience and avoidance of harmful stimuli (Roitman et al., 2008; Hu, 2016; Pultorak et al., 2018). Indeed, on tail shock as aversive stimuli, it is shown that the differential response of the dopaminergic fibers is dependent on the brain regions (i.e., upregulation of the dopaminergic activity in the prefrontal cortex but down regulation in the NAc is observed; Kim et al., 2016). This might result from the heterogeneity of the dopaminergic neurons in the midbrain projecting differentially to the distant targets such as NAc and prefrontal cortex under stress.

Accumulating studies have implicated the importance of the mesolimbic pathway in the modulation of stress-coping strategies in animals subjected to chronic stress (Berton et al., 2006; Nestler and Carlezon, 2006; Krishnan et al., 2007). Indeed, midbrain dopaminergic neurons in depressive-like mice exhibited higher firing rates than those in stress-resilient mice (Krishnan et al., 2007; Friedman et al., 2014). Phasic activation of midbrain dopaminergic neurons have been shown to induce depressivelike symptoms with passive stress-coping behaviors in mice treated with chronic stress (Chaudhury et al., 2013). However, a study using optogenetics demonstrated that the activation of midbrain dopaminergic neurons would potentiate active coping behaviors in a despair-based test, as well as induce anhedonialike behaviors (Tye et al., 2013).

These results indicate that dopamine has differential effects on stress coping that is dependent on the timing of release of dopamine as well as the brain regions. Thus, investigation of the local dopamine dynamics with subsecond temporal resolution would provide a deep insight into understanding the role of dopamine in behavioral modulation under stress.

The tail suspension test (TST) is a despair-based behavioral test useful to screen antidepressants in rodents (Steru et al., 1985; Cryan et al., 2005). Inescapable stress in this test drives the animal to adopt one of the two strategies: immobility, which is beneficial as it saves energy for future events, or struggling, which is to escape from the noxious stimulus. Despite the test's frequent use in studies using animal models of depression, few studies have addressed the temporal changes of animal behaviors and the underlying neural substrates in the TST. Studies have reported that dopamine release transiently decreased in mouse NAc on presentation of the cue previously paired with aversive stimuli (Badrinarayan et al., 2012; Oleson et al., 2012). Since dopamine has been implicated in the modulation of behavioral responses under repeated stress (Ortiz et al., 1996), we hypothesized that mesolimbic dopaminergic signaling might control stress coping strategy in the TST.

Here, to address this hypothesis, we used the electrochemical measurement of dopamine in the NAc in animals under inescapable stress, using the TST. The results demonstrated that a decrease in dopamine concentration and an increase in $\mathrm{pH}$ occurred when animals transit from passive immobility to active struggling in the TST. Optogenetic inhibition of dopamine release in NAc potentiated the struggling behavior in mice under the TST. Using in vivo genome editing to knock out the D1R gene in the NAc increased the struggling duration as well as the number of bouts in the TST. Taken together, our findings provide the first evidence that dopamine signaling in the NAc through D1R signaling modulates the behavioral shift from passive to active coping in the TST.

\section{Materials and Methods}

\section{Subjects}

All experimental procedures were performed in accordance with the Animal Experiment and Recombinant DNA Experiment Plans approved by the Committees of Hiroshima University. Eight- to 12-week-old male C57BL/6J wild type (Japan SLC) were used for all recordings and behavioral experiments. DAT-Cre knock-in mice (Bäckman et al., 2006) were used for optogenetic experiments. The mice were housed on a 12/12 h light/dark cycle (light on from 7 A.M. to 7 P.M.) schedule and ad libitum water and food.

\section{CRISPR/Cas9 plasmid construction}

The sgRNAs for Staphylococcus aureus Cas9 (SaCas9) targeting mouse Drd1 $a$ and Drd2 were designed using Benchling with parameters of 21 nucleotide spacer length and NNGRRT protospacer adjacent motif (PAM). Pairs of oligo DNAs (Hokkaido Systems Science, Sapporo) corresponding to the spacers with adaptors were synthesized, hybridized, and ligated using Quick Ligase (New England BioLabs) into linearized pX601 plasmid (plasmid \#61591, Addgene; Feng Zhang, MIT) digested with BsaI (New England BioLabs). Sequence of oligo DNAs targeting Drd1 $a$ and Drd2 genes are listed in Tables 1,2, respectively.

\section{Cel-I assay in Neuro2A cells}

Cel-I assays using Mouse Neuro2A cells were performed as described previously (Aida et al., 2015). Briefly, Drd1a-, Drd2-, or empty pX601 plasmids was transfected into Neuro2A cells in a 24 -well plate using Lipofectamine LTX (Life Technologies). After $72 \mathrm{~h}$ post-transfection, genomic DNA was isolated using a DNeasy Blood \& Tissue kit (QIAGEN). Drd1a and Drd2 loci were then PCR amplified from the purified genomic DNA with primers (Tables 1,2). PCR products were denatured, digested at $42^{\circ} \mathrm{C}$ for $30 \mathrm{~min}$ with a Surveyor Mutation Detection kit (Transgenomic), and analyzed by electrophoresis in $3 \%$ agarose gel stained with ethidium bromide. The gel images were obtained with a ChemiDoc XRS system (Bio-Rad) and analyzed by Image Lab software (Bio-Rad).

\section{Adeno-associated virus (AAV) production and purification}

$A A V$ vectors for CRISPR/Cas9 were produced and purified as described previously (Matsushita et al., 1998; Okada et al., 2005). In brief, HEK293 cells were co-transfected with pAAV vector plasmid harboring a gene of interest, pAAV-RC2, and pHelper (catalog \#VPK-422 and VPK-402; Cell Biolabs, Inc). The crude viral lysate was purified with two rounds of cesium chloride ultracentrifugation. The titer of the viral stock was determined against plasmid standards by real-time PCR with primers 5'-CAAGGCTGTTAGAGAGATAATTGGA-3' and 5' -AAAACTGCA AACTACCCAAGAAA- $3^{\prime}$ amplifying the fragment for U6 promoter; subsequently, the stock was dissolved in HN buffer [50 mM HEPES ( $\mathrm{pH}$ 7.4) and $0.15 \mathrm{M} \mathrm{NaCl}$ ] and stored at $80^{\circ} \mathrm{C}$. For optogenetic inhibition experiments, AAV5-EF1a-DIO-EYFP and AAV5-EF1a-DIO-eNpHR3.0EYFP were purchased from University of North Carolina vector core.

Injection of adeno-associated viral vectors

C57BL/6J male mice who were eight-week-old were anesthetized with pentobarbital $(50 \mathrm{mg} / \mathrm{kg}$, i.p.) and mounted onto a stereotaxic apparatus (SR-8N, Narishige) with a micromanipulator (Model 1760-61, David Kopf Instruments). The body temperature of the animal was maintained at $37^{\circ} \mathrm{C}$ by a heat pad throughout the experiment. Bilateral holes were made in the skull to target the NAc core $(1.1 \mathrm{~mm}$ anterior and $1.1 \mathrm{~mm}$ lateral to the bregma) using a microdrill. Glass capillary containing the viral solution was lowered to a depth of $4.1 \mathrm{~mm}$ from the pial surface of the brain, and $0.3 \mu \mathrm{l}$ of AAV solution (2.1-3.0 $\times 1010$ genome copies/ 
Table 1. Optimization of short guide RNA targeting murine Drd1a gene Cel-I assay and off-target prediction in silico

\begin{tabular}{|c|c|c|c|c|c|c|c|}
\hline$\overline{\text { No. }}$ & Primers & Sequence & Strand & Domain & PAM & Cleavage efficiency (\%) & Off target score (predicted) \\
\hline 1 & $\begin{array}{l}\text { Forward } \\
\text { Reverse }\end{array}$ & $\begin{array}{l}5^{\prime} \text {-CACCGATGGCTCCTAACACTTCTACC-3' } \\
5^{\prime} \text {-AAACGGTAGAAGTGTTAGGAGCCATC-3' }\end{array}$ & - & N-term & ATGGAT & 9.4 & 83.9 \\
\hline 2 & $\begin{array}{l}\text { Forward } \\
\text { Reverse }\end{array}$ & $\begin{array}{l}\text { 5'-CACCGAGATTGCTGGCTTTTGGCCCT-3' } \\
5^{\prime} \text {-AAACAGGGCCAAAAGCCAGCAATCTC-3' }\end{array}$ & - & TM2 & TTGGGT & 5.2 & 77.5 \\
\hline 3 & $\begin{array}{l}\text { Forward } \\
\text { Reverse }\end{array}$ & $\begin{array}{l}\text { 5'-CACCGCATAAATAATGGGGTTCAGGG-3' } \\
\text { 5'-AAACCCCTGAACCCCATTATTTATGC-3' }\end{array}$ & + & TM7 & AGGAAT & 0.0 & 59.9 \\
\hline 4 & $\begin{array}{l}\text { Forward } \\
\text { Reverse }\end{array}$ & $\begin{array}{l}5^{\prime} \text {-CACCGCCTGATGACAGCGGCACAGAC-3' } \\
5^{\prime} \text {-AAACGTCTGTGCCGCTGTCATCAGGC-3' }\end{array}$ & + & TM1 & AAGGGT & 12.0 & 78.0 \\
\hline 5 & $\begin{array}{l}\text { Forward } \\
\text { Reverse }\end{array}$ & $\begin{array}{l}\text { 5'-CACCGACAGACAAGGGTATTCCCTAA-3' } \\
\text { 5'-AAACTTAGGGAATACCCTTGTCTGTC-3' }\end{array}$ & + & TM2 & GAGAGT & 6.0 & 87.6 \\
\hline 6 & $\begin{array}{l}\text { Forward } \\
\text { Reverse }\end{array}$ & $\begin{array}{l}\text { 5'-CACCGCTTATCCTGTCCACTCTCTTA-3' } \\
\text { 5'-AAACTAAGAGAGTGGACAGGATAAGC-3' }\end{array}$ & - & TM1 & GGGAAT & 22.1 & 73.3 \\
\hline 7 & $\begin{array}{l}\text { Forward } \\
\text { Reverse }\end{array}$ & $\begin{array}{l}\text { 5'-CACCGGGTATTCCCTAAGAGAGTGGA-3' } \\
\text { 5'-AAACTCCACTCTCTTAGGGAATACCC-3' }\end{array}$ & + & TM2 & CAGGAT & 11.7 & 73.0 \\
\hline 8 & $\begin{array}{l}\text { Forward } \\
\text { Reverse }\end{array}$ & $\begin{array}{l}5^{\prime} \text {-CACCGCAGGGACAGAAAACAGGCTGT-3' } \\
5^{\prime} \text {-AAACACAGCCTGTTTTCTGTCCCTGC-3' }\end{array}$ & + & TM1 & GAGGAT & 23.7 & 48.4 \\
\hline
\end{tabular}

Table 2. Optimization of short guide RNA targeting murine Drd2 gene by Cel-I assay and off-target prediction in silico

\begin{tabular}{|c|c|c|c|c|c|c|c|}
\hline No. & Primers & Sequence & Strand & Domain & PAM & Cleavage efficiency (\%) & Off target score (predicted) \\
\hline \multirow[t]{2}{*}{1} & Forward & 5'-CACCGAAGATGTCACAGTGAATCCTG-3' & \multirow[t]{2}{*}{-} & \multirow[t]{2}{*}{ TM3 } & \multirow[t]{2}{*}{ CTGAAT } & \multirow[t]{2}{*}{0.0} & \multirow[t]{2}{*}{65.9} \\
\hline & Reverse & 5'-AAACCAGGATTCACTGTGACATCTTC-3' & & & & & \\
\hline 2 & Forward & 5'-CACCGCGGTGCAGAGTTTCATGTCCT-3' & - & IC3 & CAGGGT & 0.0 & 74.4 \\
\hline \multirow[t]{2}{*}{3} & Forward & 5'-CACCGTTAGACTTCATGATAACGGTG-3' & \multirow[t]{2}{*}{-} & \multirow[t]{2}{*}{ IC3 } & \multirow[t]{2}{*}{ CAGAGT } & \multirow[t]{2}{*}{ NA } & \multirow[t]{2}{*}{91.2} \\
\hline & Reverse & 5'-AAACCACCGTTATCATGAAGTCTAAC-3' & & & & & \\
\hline 4 & Forward & 5'-CACCGACCGTTATCATGAAGTCTAAT-3' & + & IC3 & GGGAGT & NA & 89.1 \\
\hline 5 & Reverse & 5'-AAACCGCCTGTTCACTGGGAAACTCC-3' & + & IC3 & GAGAAT & 5.1 & 84.6 \\
\hline \multirow[t]{2}{*}{6} & Forward & $5^{\prime}$-CACCGCATCGTACCAGGACAGGTTCA-3' & \multirow[t]{2}{*}{-} & \multirow[t]{2}{*}{$\mathrm{N}$-term } & \multirow[t]{2}{*}{ GTGGAT } & 3.7 & 88.8 \\
\hline & Reverse & 5'-AAACTGAACCTGTCCTGGTACGATGC-3' & & & & & \\
\hline 7 & Forward & $5^{\prime}$-CACCGAGAACTGGAGCCGGCCCTTCA-3' & + & $\mathrm{N}$-term & ATGGGT & 0.0 & 84.0 \\
\hline & Reverse & 5'-AAACTGAAGGGCCGGCTCCAGTTCTC-3' & & & & & \\
\hline 8 & Forward & $5^{\prime}$-CACCGAAAGACGATGATAAAGATGAG-3' & - & TM1 & GAGGGT & 9.5 & 49.9 \\
\hline & Reverse & 5'-AAACCGCTTGGAGCTGTAGCGTGTGC-3' & & & & & \\
\hline 11 & Forward & 5'-CACCGTACTGTCATGATCGCCATTGT-3' & + & TM4 & CTGGGT & 7.2 & 85.0 \\
\hline & Reverse & $5^{\prime}$-AAACACAATGGCGATCATGACAGTAC-3' & & & & & \\
\hline
\end{tabular}

$\mathrm{ml}$ ) was injected into the NAc bilaterally at a speed of $0.02 \mu \mathrm{l} / \mathrm{min} .10$ min after the injection, the glass capillary was withdrawn gently from the brain. For optogenetic inhibition experiments, male DAT::Cre mice were injected with AAV5-EF1a-DIO-EYFP or AAV5-EF1a-DIO-eNpHR3.0EYFP bilaterally in VTA region ( $N=9$ for each group). For gene knockout experiments, wild-type mice were injected with AAVs for CRISPR/ Cas9 targeting the Drd1a or Drd2 genes in NAc ( $N=15$ for each group). After the histologic analysis of the injection sites, mice with mistargeting were excluded for the behavioral analysis.

The skin was then sutured, and the animals were allowed to recover for four weeks before the behavioral experiments.

Next generation sequencing of the genomic DNA after genome editing Mice that received AAV vectors carrying CRISPR/Cas9 cassette targeting Drd1a [AAV-CMV-SaCas9-U6-sgRNA(Drd1a), N=3], Drd2 [AAVCMV-SaCas9-U6-sgRNA(Drd2), $N=3$ ] and BsaI site as control [AAVCMV-SaCas9-U6-sgRNA(BsaI), $N=3$ ] were used. Fourteen days after $\mathrm{AAV}$-injections targeting the NAc, mice were killed to collect tissue punches of the NAc in 500- $\mu$ m-thick sections. Genomic DNA was subsequently extracted and quantified (Qubit fluorometer, ThermoFisher
Scientific). One nanogram of genomic DNA was used to amplify the fragment flanking the PAM sequence of the genes using the following primer sets (lowercase and uppercase letters represent the adapters for sequencing and gene-specific sequence, respectively): 5 '-acactctttccctac acgacgctcttccgatctGAGTGATTGGGGGAAGTCTG-3' and 5'-gtgactg gagttcagacgtgtgctcttccgatctTGTCAAAGGCTACCCAAATG-3' for Drd1a; 5'-acactctttccctacacgacgctcttccgatctGACAAGGGGGAAGGTCTTAG-3' and 5 '-gtgactggagttcagacgtgtgctcttccgatctTCCAGCCTCCTTAGAGTTAG$3^{\prime}$ for Drd2. Sequencing was performed using MiSeq (Illumina) with the MiSeq Reagent Kit Nano ver 2 (Illumina).

Behavioral tests

All behavioral tests were performed after habituation of the mice to the test room for at least $1 \mathrm{~h}$ before the test.

Open-field test

An open-field arena $(50 \times 50 \times 40 \mathrm{~cm})$ under the illumination 500 lux was used for the test. Mice were placed at the corner of the arena, and movement of the animals was recorded for 30 min using a CCD camera at $60 \mathrm{fps}$. Video images were subsequently processed for analysis using 
an ImageOF (Mouse Phenotype Database; http://www.mouse-phenotype. org/software.html) based on the ImageJ program (Schneider et al., 2012; https://imagej.nih.gov/ij/).

TST

The tail of the mouse was suspended by attaching the tail to a smooth Plexiglas plate, and the mouse was hung from the roof of a sound attenuation box. Animal movement was recorded using a camera for $6 \mathrm{~min}$. After that, the duration of the animal's immobility was scored and analyzed using ImageFZ software (Mouse Phenotype Database; http://www. mouse-phenotype.org/software.html). Criteria for the immobile and struggling sessions were set as immobile and struggling for longer than $3 \mathrm{~s}$ each. For the temporal analysis of immobility, the time spent immobile was calculated with bins of $60 \mathrm{~s}$. To analyze the effect of repeated exposure to the TST on behaviors, a group of mice were subjected to a second TST $48 \mathrm{~h}$ after the first TST. For simultaneous recording of the behavior with fast scanning cyclic voltammetry (FSCV), a TTL signal generated by stimulator (Master-8 PULSE STIMULATOR, A.M.P.I.) was used to synchronize the FSCV signal with the behavioral video recorded at 10 frames per second in the TST. To detect the behavioral events, we first identified the immobile behaviors by $<5 \%$ pixels change from the previous frame in the body (including head, trunk, limbs, and tail) lasting longer than $3 \mathrm{~s}$. Then, frames with $>5 \%$ pixels' change lasting longer than $3 \mathrm{~s}$ were identified as struggling. To analyze the dopamine and $\mathrm{pH}$ fluctuation in freely behaving animals, baseline of dopamine and $\mathrm{pH}$ was obtained by subtracting the background signal 10 $s$ before each behavioral transition. By preliminary temporal analysis of the mouse body movement in TST, we observed duration of single struggling bout was shorter than $20 \mathrm{~s}$ (mean half peak width \pm SEM, $7.35 \pm 3.56 \mathrm{~s}$ ). To cover the transition between immobility and struggling and a half of the struggling bout duration, temporal window starting $10 \mathrm{~s}$ before and ending $10 \mathrm{~s}$ after the transition between immobility and struggling was used for analysis of the dopamine and $\mathrm{pH}$ change.

\section{Histology}

For immunohistochemistry, animals were killed using an overdose of ketamine and fixed by transcardiac perfusion of $4 \%$ paraformaldehyde (PFA) in $0.1 \mathrm{M}$ PBS (pH 7.4) two weeks after AAV injection. After postfixation overnight, $50-\mu \mathrm{m}$-thick sections (100 $\mu \mathrm{m}$ apart) were cut using a vibratome and processed for immunohistochemistry. Sections containing the NAc from different groups were stained together for further semi-quantification. Monoclonal mouse anti-hemagglutinin (HA; 1:1000, RRID: AB_2565335, 901513, BioLegend), polyclonal guinea pig anti-dopamine receptor 1 (1:500, RRID: AB_2571595, D1R-GP-Af500, Frontier Institute Co Ltd), polyclonal rabbit anti-dopamine receptor 2 (1:500, RRID: AB_2571596, D2R-RbAf960, Frontier Institute Co Ltd; Narushima et al., 2006; Uchigashima et al., 2007), donkey anti-mouse IgG-Alexa Fluor 488 (1:1000, RRID:AB_ 2732856, ab150105, Abcam), donkey anti-mouse IgG-Alexa Fluor 594 (1:1000, RRID:AB_2340621, 711-585-152, Jackson ImmunoResearch), and donkey anti-guinea pig IgG-Alexa Fluor 594 (1:1000, RRID:AB_2340475, 706-586-148, Jackson ImmunoResearch) were used for fluorescent immunostaining. After the primary and secondary antibody reactions, sections were counterstained with DAPI.

Quantification of the D1R and D2R protein after immunostaining was done using sections containing the NAc. Images were acquired using a confocal laser scanning microscope (LSM510 PASCAL, Zeiss) under the same gain and offset between groups. Region of interest (ROI) for the integrated intensity analyses was determined by choosing the area with cells immunoreactive to the HA as a tag to SaCas9. Mean integrated intensity was then calculated by dividing the integrated intensity with the area of the ROI using ImageJ.

For identification of the recording sites, the animals were killed by an overdose of pentobarbital sodium and fixed by transcardiac perfusion of $4 \%$ PFA; $100-\mu \mathrm{m}$-thick sections were cut and stained with thionine for Nissl staining.

\section{Carbon fiber electrodes fabrication}

Dopamine measurement in freely behaving animals was performed by implanting microsensors in vivo as reported before, with a slight modification (Clark et al., 2010). Carbon fiber microsensors for chronic implantation were made by inserting a $7-\mu \mathrm{m}$ carbon fiber (T650, Goodfellow Corporation) into a $10-\mathrm{mm}$ in length fused silica tube (diameter $20 \mu \mathrm{m}$, Polymicro Technologies). One end of the microsensor was sealed with 30-min Devcon epoxy (ITW Devcon). Excessive epoxy on the carbon fiber was removed by acetone. Epoxy seal was allowed to cure overnight at room temperature before use. The other end of the exposed carbon fiber electrode was connected to a half pitch gold pin using electroconductives (Dotite, Fujikura Kasei Co, Ltd). Ultravioletsensitive dental resin was applied to strengthen the connection between the gold pin and the carbon fiber electrode. The protruded carbon fiber length was then trimmed to around $150 \mu \mathrm{m}$ under a microscope with ocular micrometer. Before use, all microsensors were soaked in purified isopropanol for at least $10 \mathrm{~min}$ to increase sensitivity (Bath et al., 2000).

\section{FSCV}

Before the in vitro calibration, microsensors were etched at $60 \mathrm{~Hz}$ for $30 \mathrm{~min}$ using a triangular scanning waveform from $-0.4 \mathrm{~V}$ (vs $\mathrm{Ag} / \mathrm{AgCl}$ ) to $1.3 \mathrm{~V}$ and back to $-0.4 \mathrm{~V}$ at a scan rate of $400 \mathrm{~V} / \mathrm{s}$ to increase the stability of baseline and sensitivity. Implantations were performed on deeply anesthetized eight-week-old male C57BL/6J mice. Mice were anesthetized with pentobarbital $(50 \mathrm{mg} / \mathrm{kg}$, i.p.) and affixed to the stereotactic apparatus (SR-8N, Narishige). Four anchor screws were placed on the skull, and a microsensor was implanted in the NAc (1.1 mm anterior and $1.1 \mathrm{~mm}$ lateral to the bregma and $4.1 \mathrm{~mm}$ deep). A parallel bipolar stimulating electrode (MS303/3-B/SPC, Plastic One) targeting the medial forebrain bundle (MFB) was implanted $1.3 \mathrm{~mm}$ posterior and $1.3 \mathrm{~mm}$ lateral to the bregma and $5.0 \mathrm{~mm}$ deep. $\mathrm{Ag} / \mathrm{AgCl}$ reference electrodes (E255A, In Vivo Metric) were pretreated with Nafion coating to avoid the potential shift of the oxidative peak of dopamine as reported previously (Hashemi et al., 2011). $\mathrm{Ag} / \mathrm{AgCl}$ reference electrodes were then implanted on the contralateral side of the brain at a convenient location. Position of the stimulating electrode was adjusted until a clear dopamine response was observed when MFB was stimulated. Dental cement was used to fix the electrodes and anchor screws onto the skull. Animals were allowed to recover for at least $5 \mathrm{~d}$ before the recordings.

The FSCV recording and MFB stimulation were done by a multifunction input/output device (PCIe-6363, National Instruments) triggering the isolating stimulator (Isoflex, A.M.P.I.) and HDCV software (Bucher et al., 2013). Triangular waveform was ramped from -0.4 to 1.3 $\mathrm{V}$ (vs $\mathrm{Ag} / \mathrm{AgCl}$ ) and back to $-0.4 \mathrm{~V}$ at a scan rate of $400 \mathrm{~V} / \mathrm{s}$. Cyclic scans were repeated every $100 \mathrm{~ms}$ to obtain a $10-\mathrm{Hz}$ sampling rate, and microsensors were applied with $-0.4-\mathrm{V}$ potential between scans. Mice implanted with microsensor were used for the recording in freely behaving conditions. Before the recording, microsensors were connected to a custom-made head-mounted amplifier (Takmakov et al., 2011) and habituated to the recording box for $1 \mathrm{~h}$. Animal behaviors were recorded at $60 \mathrm{fps}$ (AQ-VU, TEAC), and synchronized with the FSCV signal by a TTL signal generated from the multifunction input/output device. At the end of the tail suspension recording, an MFB stimulation (60 pulses, $60 \mathrm{~Hz}$ for $1 \mathrm{~s}$ ) was delivered to the freely behaving animal to obtain the evoked dopamine release as reference. After the recording, an electrolytic lesion current was delivered to the microsensor to verify the recording site in the NAc.

\section{Optogenetics}

Optogenetic experiments was performed as described before with a slight modification (Tye et al., 2013). DAT::Cre mice were injected with AAV5-EF1 $\alpha$-DIO-EYFP or AAV5-EF1 $\alpha$-DIO-eNPHR3.0-EYFP in VTA region (AP: $-3.2 \mathrm{~mm}$, ML: $0.35 \mathrm{~mm}$, DV: $4.2 \mathrm{~mm}$ ). Two weeks after AAV injection, mice were implanted with two custom made fiberoptical cannulae with protrusion of $10 \mathrm{~mm}$ (CFLC230-10, Thorlabs) using the procedure described above for the implantation of carbon fiber electrode. NAc was targeted with micromanipulator tilted to $5^{\circ}$ (AP: $1.0 \mathrm{~mm}$, ML: $1.3 \mathrm{~mm}$, DV: $3.8 \mathrm{~mm}$ ). Fiber-optical cannulae were connected to a Y-shaped dual polymer optical fiber for bilateral inhibition (OptogeneticsFiber- $2 \times 500$, Goldstone Scientific) using zirconia sleeves. Optogenetic inhibition was performed from 180 to $240 \mathrm{~s}$ after the onset of the TST in both 


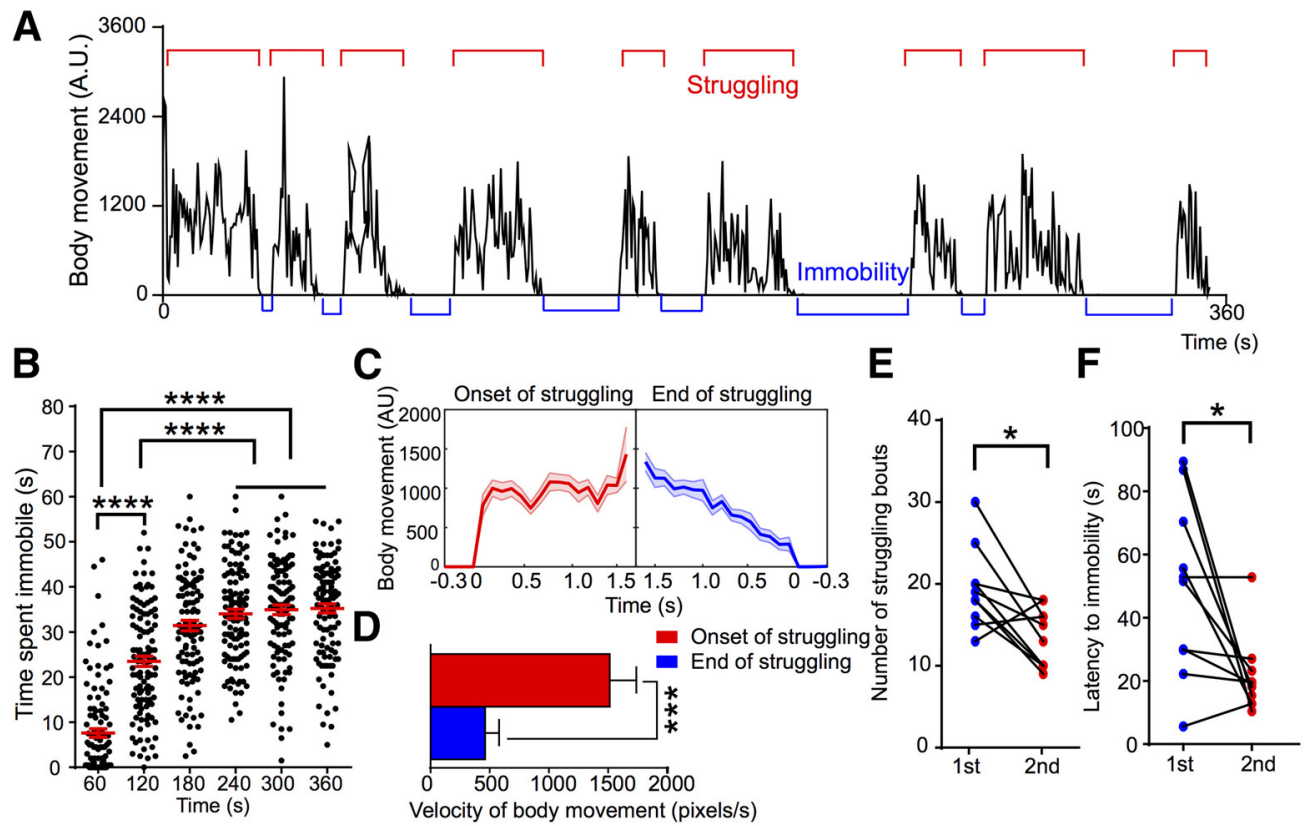

Figure 1. Alternative stress-coping behaviors in mice under the tail suspension stress. $A, A$ line plot showing time course of body movement of a C57BL/6J male mouse under the tail suspension stress condition with alternations between struggling (red bracket) and immobility (blue bracket). $\boldsymbol{B}$, Scatter plot of time spent immobile under the tail suspension stress condition showing an increase in the immobile behavior in the latter stage (from 180 to $360 \mathrm{~s}$ ) of the test than in the initial stage (from 60 to $120 \mathrm{~s}$ ) by dividing a 360 -s test into six bins ( $N=111$ mice; ${ }^{* * * *} p<0.0001$ one-way ANOVA followed by Tukey's multiple comparison test). C, Line plots of temporal changes in mean body movement of mice under tail suspension during the onset (red) and offset (blue) of the struggling bouts. Shaded area represents the SEM. D, A bar graph of the velocity of body movement during the onset (red) and end (blue) of the struggling bouts. Values are represented as mean $\pm S E M$; ${ }^{* * *} p<0.001$. $E, F$, Scatter plots showing the number of struggling bouts and the latency to immobility of the mice in the first (blue) and second TST $\left(N=10\right.$ mice; ${ }^{*} p<0.05$, paired $t$ test $)$.

group of mice through a LED light source (M595F2, Thorlabs) connected to a stimulator (Master-8 PULSE STIMULATOR, A.M.P.I.).

\section{FSCV data analyses}

In vitro calibration of dopamine and $\mathrm{pH}$ was done using a flow injection system. Dopamine ranging from 25 to $125 \mathrm{~nm}$ and an artificial CSF (ACSF) solution with $\mathrm{pH}$ from 7.0 to 7.5 were used to calibrate the microsensor (Clark et al., 2010). Analyses of the in vivo recording was done using the HDCV Analysis software (Bucher et al., 2013). The in vivo training sets of dopamine and $\mathrm{pH}$ for the principal component regression were obtained from the stimulation of MFB in each mouse. After extraction of the dopamine concentration from the signal by principal component regression, data for each trial (totally 55 trials) from five mice was inspected and analyzed using custom-written MATLAB scripts.

\section{Statistical analysis}

Test of mean difference between groups were analyzed by the two-tailed Student's $t$ test for two groups of data and one-way ANOVA followed by Tukey's post hoc test for multiple comparisons for data with three or more groups unless otherwise specified. We applied paired $t$ test and two-way repeated measures ANOVA followed by Sidak's post hoc test to the subjects in Figure 1E,F and the optogenetic experiment data, respectively. Analyses were done using SPSS Statistics 19 software (IBM) and GraphPad Prism (GraphPad Software Inc.). The level of significance was defined as $p<0.05$, and all values are indicated as mean \pm SEM, if not specified otherwise.

\section{Results}

\section{Alternate active and passive coping behaviors observed} under tail suspension stress

To study the animals' stress-coping strategy during inescapable stress, we analyzed temporal changes of the body movement of the mice in the TST. Mice stereotypically exhibited alternations between struggling (Fig. 1A, red brackets) and immobility (Fig. $1 A$, blue brackets). The alternation of the two strategies became more obvious during the latter part of the tail suspension session, showing longer intervals of immobility between struggling bouts i.e., $180 \mathrm{~s}$ after the start of the session (one-way ANOVA, $F_{(5,660)}$ $=2.505, p<0.0001$; Fig. $1 B$ ). Interestingly, detailed analysis revealed that the body movement at the onset of struggling was faster than at the end $(p<0.001$; Fig. $1 C, D)$, implying the presence of a brain machinery underlying such transitions from immobility to struggling. These consistent transition between two states were more frequently found on the first day of the TST than during the subsequent test after the second day, as we observed a decrease in the number of struggling bouts (paired $t$ test, $t_{(9)}=3.134, p=0.012$; Fig. $1 E$ ) and latency to immobility (paired $t$ test, $t_{(9)}=2.850, p=0.019$; Fig. $1 F$ ). Thus, for the further examination of the neural substrate underlying the initiation of struggling, we focused on the behavior of mice naive to the TST.

\section{Reduction of dopamine release in the NAc while} transitioning from immobility to struggling during the TST To address a role of dopamine in controlling the transition between immobility and struggling during the TST at subsecond resolution, we measured the extracellular dopamine levels using FSCV with carbon fiber-based microsensors (Fig. 2A; Clark et al., 2010). Flow injection analysis in vitro revealed that the microsensor exhibited a high sensitivity for dopamine $(0.405 \mathrm{nA} / \mathrm{nM})$ and $\mathrm{pH}$ change $(-0.408 \mathrm{nA} / \mathrm{pH}$; Fig. $2 B-D)$, exhibiting a strong linear correlation of the dopamine concentration or $\mathrm{pH}$ change with the current measured by the microsensor $[p<0.0001$, Pearson $r=0.9997$ (Fig. 2C) and $p<0.0001$, Pearson $r=$ -0.9995 (Fig. 2E)]. The sensitivity was further substantiated by application of the sensor to the in vivo measurement of dopamine in the NAc by stimulation of the MFB, which the cyclic voltammogram peaked at $0.6 \mathrm{~V}$ consistent with the known oxidative peak of dopamine that typically follows (Fig. $2 F$ ). The 
A

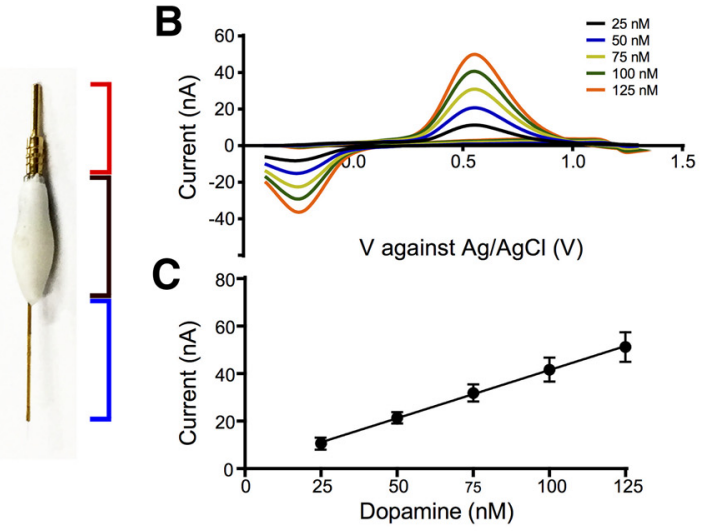

$\mathbf{F}$

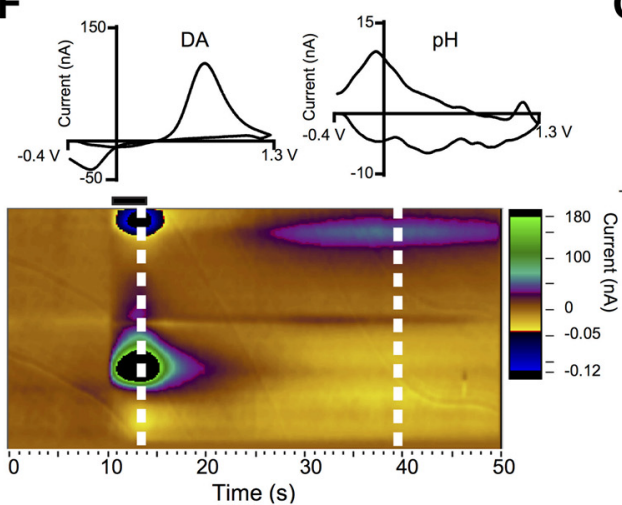

G Tratining setorofonanine

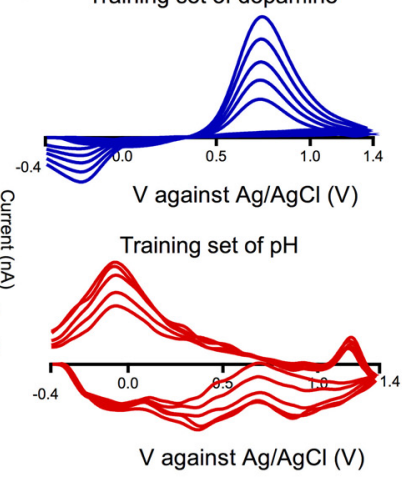

D
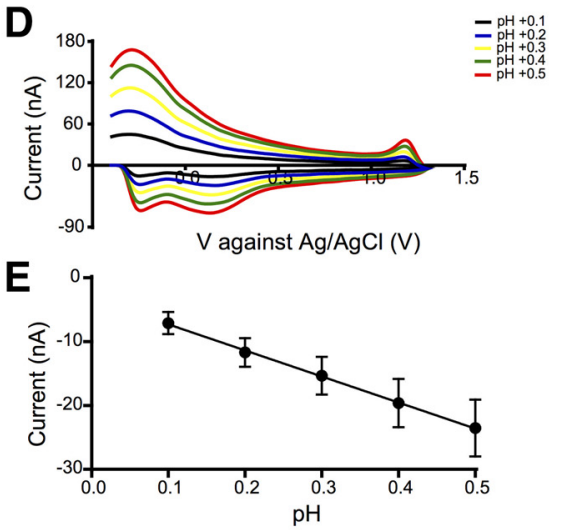

H

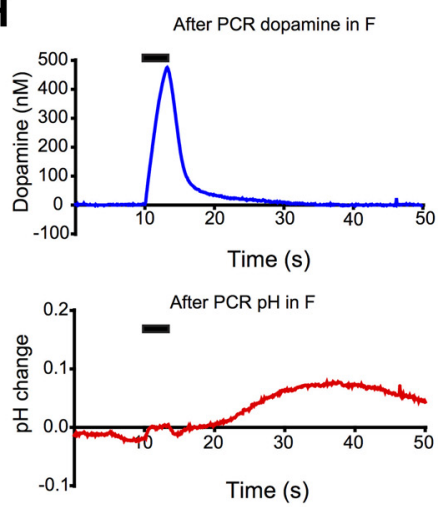

Figure 2. Detection of dopamine using the carbon fiber microsensors in vitro and in vivo. $A$, Carbon fiber microsensor used for the in vitro and in vivo experiments. It consists of carbon fibers encased in a fused silica tube (blue bracket) and a gold pin (red bracket) connected with an adhesive, which is electrically conductive, and a dental resin (black bracket). $\boldsymbol{B}$, Background-subtracted cyclic voltammograms of five different concentrations of dopamine tested in vitro using the microsensors. C, Dopamine concentration/current response curve obtained from in vitro calibrations $(N=8)$. $\boldsymbol{D}$, Background-subtracted cyclic voltammograms of five different $\mathrm{pH}$ increase tested in vitro. $(\boldsymbol{E}) \mathrm{pH}$ change/current response curve obtained from in vitro calibrations $(N=10)$. $\boldsymbol{F}$, Color plot of dopamine release and pH shift elicited by in vivo stimulation of the MFB $(60 \mathrm{~Hz}, 180$ pulses at $120 \mu \mathrm{A}$; black bar). $\mathbf{G}$, Representative dopamine and pH training sets obtained from MFB stimulations and used for principal component regression (PCR). $\boldsymbol{H}, \mathrm{PCR}$-extracted dopamine concentration change (top) and pH shift (bottom) from $\boldsymbol{F}$ MFB stimulation. Error bars represent the SEM.

same analysis also corroborated the basic shift of tissue $\mathrm{pH}$ at the recording site with increased $\mathrm{pH}$ which presumably resulted from the increased blood flow on removal of carbon dioxide after the stimulation which is associated with increased neuronal excitability (Chesler, 2003; Venton et al., 2003).

To quantify the extracellular dopamine and $\mathrm{pH}$ change in vivo with statistical validity, we performed a principal component regression analysis of the voltammetric recordings in the NAc with electrical stimulation of the MFB (Heien et al., 2005). Using training datasets that detect differential levels of dopamine (Fig. 2G, top) and pH (Fig. 2G, bottom), the analysis successfully extracted the signal for the released dopamine; a continuous increase in the released dopamine during stimulation and an immediate decay after cessation of stimulation, reflecting the activity of dopamine transporters, was observed (Fig. $2 \mathrm{H}$, top). PCR also allowed us to check the temporal changes of $\mathrm{pH}$ at the same recording site, demonstrating the gradual increase of $\mathrm{pH}$ on a basic shift for the increased neuronal excitability, which lasted for $60 \mathrm{~s}$ from the onset of recording (Fig. $2 \mathrm{H}$, bottom).

We applied this strategy to examine the temporal dynamics of dopamine in the NAc underlying the behavioral transition of animals under tail suspension stress. According to histologic verification, the majority of our recordings were found in the core region of the NAc (Fig. $3 A$ ). We characterized the dopamine concentration fluctuations when the behavior changed between the immobile and struggling states under the TST. In FSCV recordings in the freely behaving animals under the TST, we frequently observed a transient reduction of the current at the oxidative peak of $0.6 \mathrm{~V}$ consistent with dopamine in the NAc when the mice switched from the immobile phase (Fig. $3 B$, blue) to the active struggle phase (Fig. $3 B$, red). Signal extracted by PCR indicated that the reduction of extracellular dopamine levels preceded the onset of struggling as represented by increased body movement (Fig. 3C, bottom, red dashed line). Population analyses of all bouts of struggling in the TST revealed that significant reduction of extracellular dopamine in NAc started 3.826士 $0.685 \mathrm{~s}$ before the onset of struggling, indicating that the changes in dopamine metabolism preceded the behavioral outcome. This resulted in the reduction of extracellular dopamine levels before and after the onset of struggling in the TST $\left(p=0.0066, t_{(108)}=\right.$ 2.771, two-tailed Student's $t$ test; Fig. $3 D, E$ ).

Concurrently, we also observed a basic shift in the $\mathrm{pH}$ that was accompanied by a decrease in the dopamine levels during the switch from immobility to struggling in the TST (Fig. 4A). This change occurred later than the onset of dopamine reduction i.e., $0.891 \pm 0.573 \mathrm{~s}$ after the onset of struggling $(p=4.226 \times$ $10^{-7}, t_{(108)}=5.283$, two-tailed Student's $t$ test; Fig. $4 B$ ). Quantitative analysis revealed a significant shift of $\mathrm{pH}$ toward basic values during the transition from immobile to struggling behaviors $\left(p=0.0025, t_{(108)}=3.101\right.$, two-tailed Student's $t$ test; Fig. 4E).

These changes were unique to the struggling onset because we did not observe any changes of extracellular dopamine $\left(p=0.2899, t_{(86)}=1.065\right.$, two-tailed Student's $t$ test; Fig. $\left.5 A, B\right)$ 
A
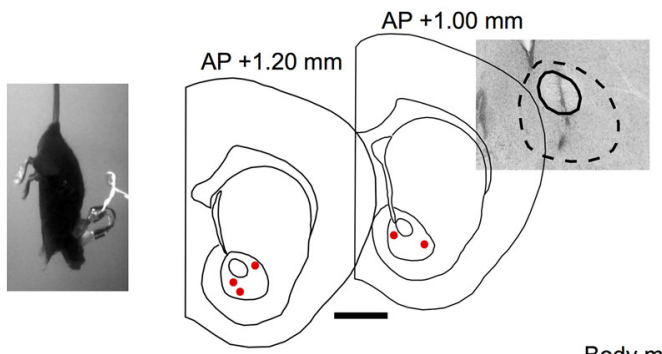

C

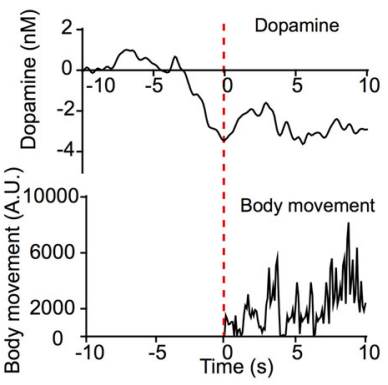

B

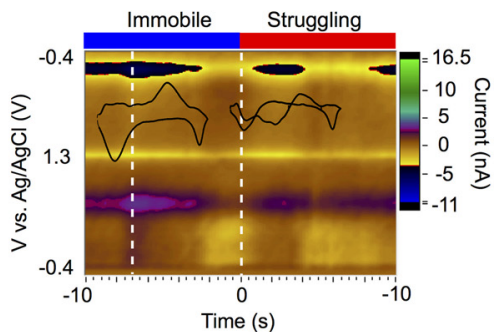

D

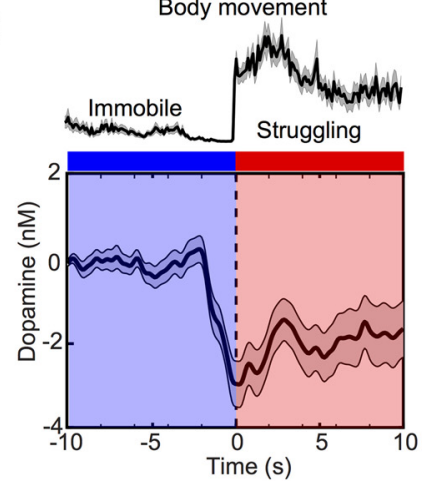

E - Immobile
- Struggling

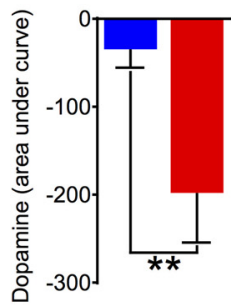

Figure 3. Reduction of dopamine release in NAc while transitioning from immobility to struggling during tail suspension. $A$, Schematic diagram of a mouse engaging in a FSCV recording during tail suspension (left). Histologically verified recording sites in the NAc (right) for all animals. $\boldsymbol{B}$, A representative color plot of cyclic voltammogram showing dopamine release while the mouse's behavior changed from the immobility to the struggling stage. Inset represents the background-subtracted cyclic voltammogram of dopamine. C, Synchronization of dopamine concentration change (top) and body movement of mice under the TST (bottom). D, Event-triggered average of body movement (top) and extracellular dopamine concentration (bottom) during the transition from the immobile to the struggling stage $(N=5$ mice; 55 trials). Shaded areas represent the mean \pm SEM. $\boldsymbol{E}$, Quantification of dopamine concentration before and after the onset of struggling behavior. Summation of dopamine concentration in the NAc for $10 \mathrm{~s}$ before (blue bar) and after (red bar) the transition from immobile to struggling behavior was calculated as the area under the curve in all trials ( $N=5$ mice; 55 trials, ${ }^{* *} p<0.001$, two-tailed Student's $t$ test). Error bars represent the SEM. Scale bar: $1 \mathrm{~mm}(\boldsymbol{A})$.
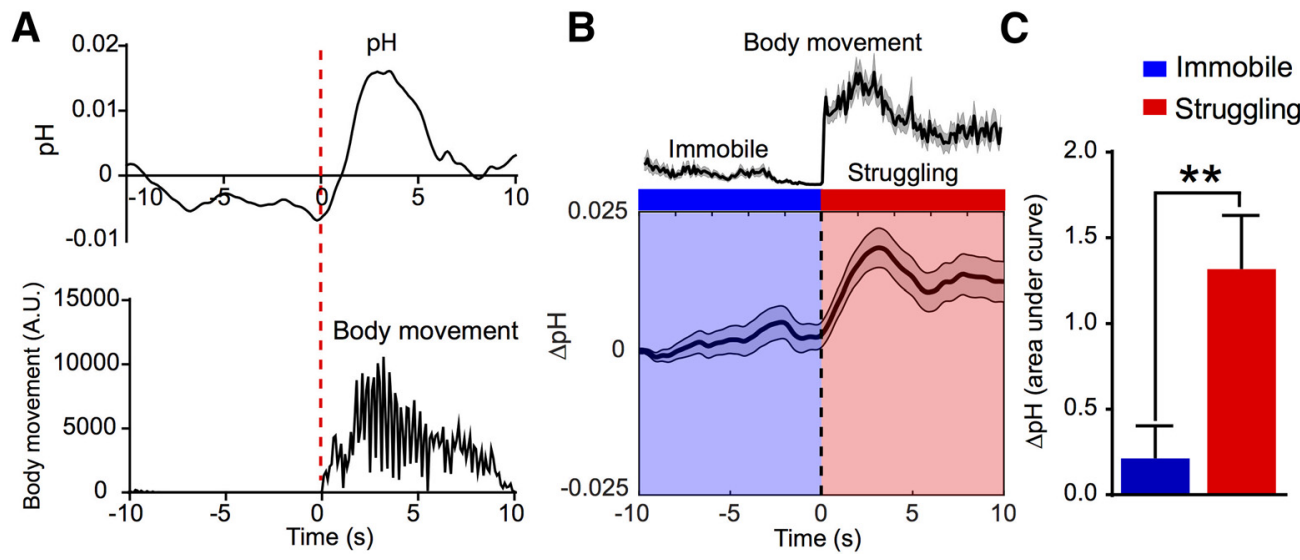

Figure 4. Basic shift of pH in NAc during the transition from the immobility to the struggling stage under the TST. $A, A$ representative trial showing synchronization of pH increase (top) and body movement of mice under tail suspension stress (bottom). $\boldsymbol{B}$, Event-triggered average of the body movement (top) and extracellular pH change (bottom) during the transition from the immobile to the struggling stage ( $N=5$ mice; 55 trials). Shaded areas represent mean \pm SEM. C, Quantification of pH change before and after the onset of struggling behavior. Summation of $\mathrm{pH}$ in the NAc for $10 \mathrm{~s}$ before (blue bar) and after (red bar) the transition from the immobile to the struggling behaviors was calculated as the area under the curve in all trials $(N=5$ mice; 55 trials, ${ }^{* *} p<0.001$, two-tailed Student's $t$ test). Error bars represent the SEM.

and $\mathrm{pH}\left(p=0.3354, t_{(86)}=0.9688\right.$, two-tailed Student's $t$ test; Fig. $5 C, D)$ during a shift from struggling to immobility under the TST. These results suggest a critical role of dopaminergic transmission in the NAc in active coping behaviors under the TST

\section{Optogenetic inhibition of dopaminergic transmission in} NAc facilitates active coping in the TST

To check a causal relationship between reduced dopamine release in NAc and struggling for active coping in the TST, we induced expression of enhanced halorhodopsin (eNpHR3.0) in the midbrain dopaminergic neurons by injection of AAV to the ventral tegmental area of the DAT::Cre mice (Fig. 6A). Fourteen days after the injection of AAV5-EF1a-DIO-EYFP or AAV5EF1a-DIO-eNpHR3.0-EYFP, DAT::Cre mice were implanted with fiber-optic cannulae targeting NAc to inhibit the dopamine release during the TST (Fig. $6 B, C$ ). Injection of the AAVs to $D A T:: C r e$ mice enabled specific labeling of the dopaminergic neurons projecting the axons to NAc with EYFP or eNPHR3.0EYFP (Fig. 6D). Since mice stabilized the duration of struggling from $180 \mathrm{~s}$ after the onset of the TST (Fig. 1B), we photo-inhibited the dopaminergic terminals in NAc by applying yellow light 
A

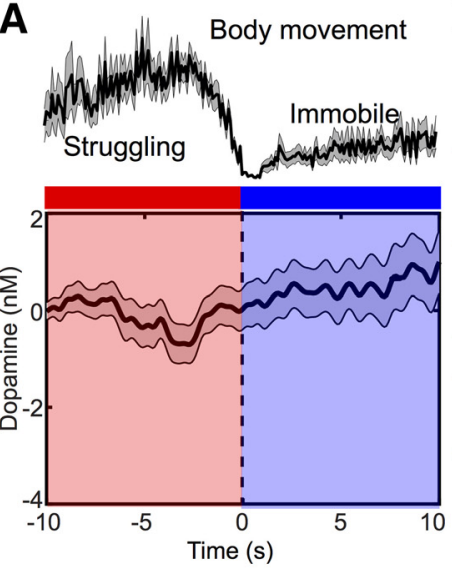

B

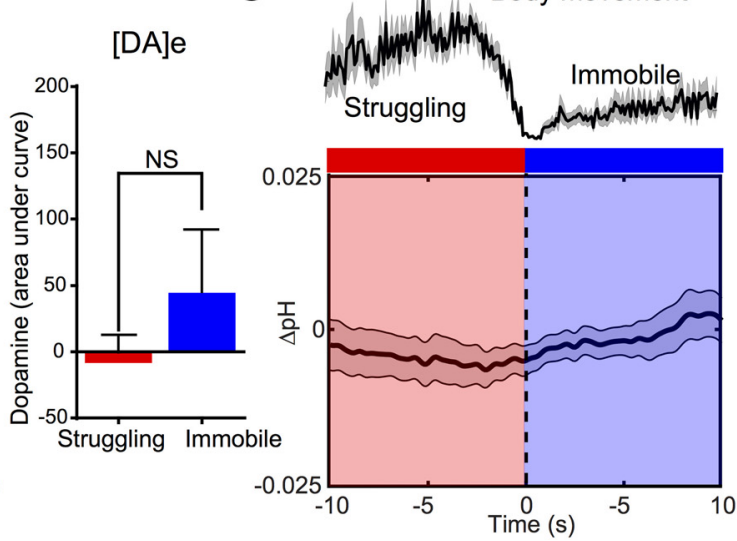

D

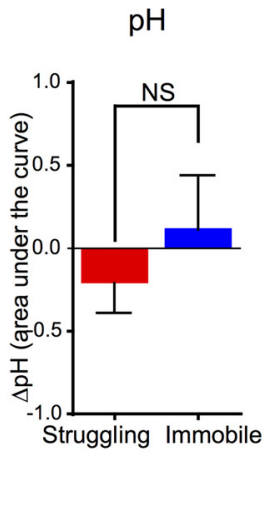

Figure 5. Extracellular dopamine release and $\mathrm{pH}$ change during the animals' switch from the struggling to the immobility stage under the TST. $A$, Event-triggered average of the body movement (top) and extracellular dopamine change (bottom) during the transition from the struggling to the immobile stage ( $N=5$ mice; 44 trials). Shaded areas represent mean \pm SEM. $\boldsymbol{B}$, Quantification of dopamine change before and after the onset of immobile behavior. Summation of dopamine in NAc for $10 \mathrm{~s}$ before (red bar) and after (red bar) the transition from struggling to immobile behaviors was calculated as the area under the curve in all trials. $C$, Event-triggered average of the body movement (top) and extracellular pH change (bottom) during the transition from the struggling to the immobile stage ( $N=5$ mice; 44 trials). Shaded areas represent mean \pm SEM. D, Quantification of pH shift before and after the onset of immobile behavior. Summation of pH in NAc for $10 \mathrm{~s}$ before (red bar) and after (red bar) the transition from the struggling to the immobile behaviors was calculated as the area under the curve in all trials ( $N=5$ mice; 44 trials, NS, not significant, two-tailed Student's $t$ test). Error bars represent the SEM.

A

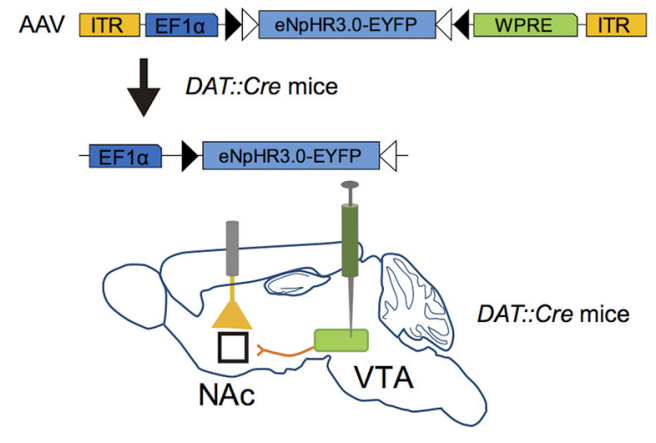

D
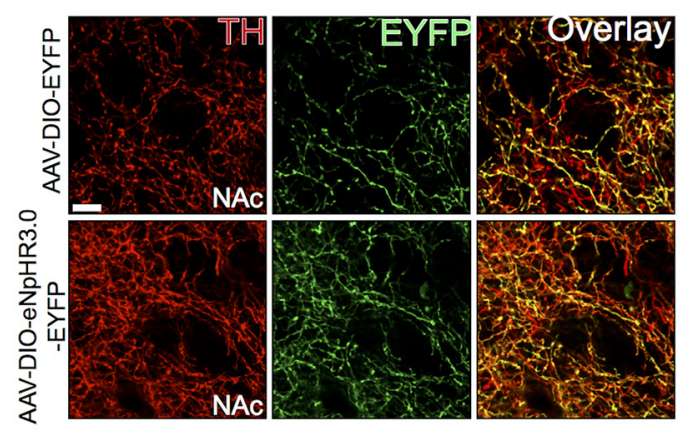

B

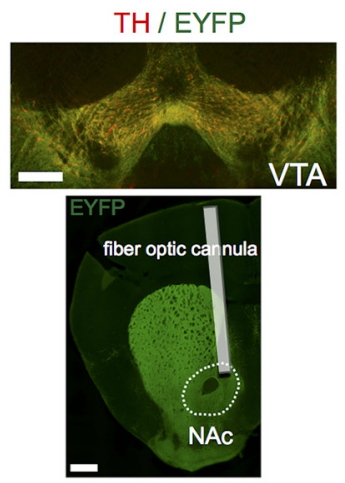

C

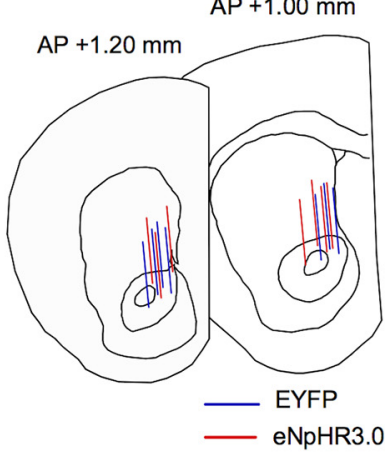

E

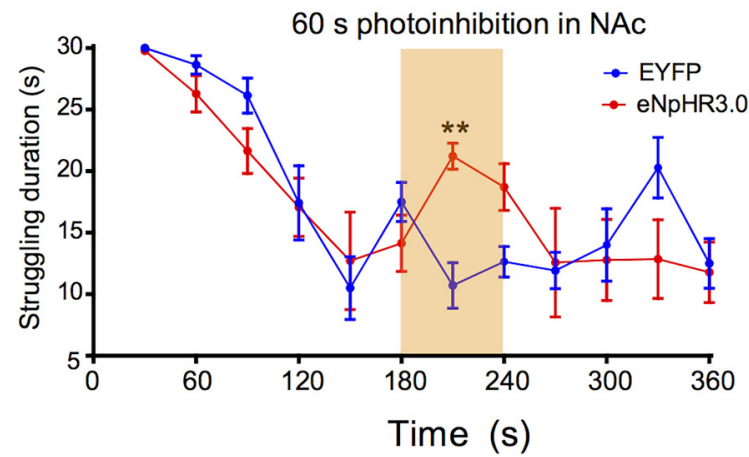

Figure 6. Optogenetic inhibition of dopaminergic terminals in NAc promotes struggling behavior during the TST. $\boldsymbol{A}$, Schematic diagram showing injection of Cre-dependent AAV expressing EYFP or eNPHR3.0-EYFP in VTA dopaminergic neurons of DAT::Cre mice. Optogenetic inhibition of dopaminergic terminals was performed in the NAc by implantation of fiber-optic cannula. $\boldsymbol{B}$, Representative images of the VTA (top) and striatum (bottom) showing successful transduction of AAV expressing EYFP (green) and tyrosine hydroxylase protein (TH, red) in DAT:: (re mice. A white vertical bar depicts a representative position of the implanted optical fiber. Dotted line encircles the nucleus accumbens core. C, Schematic representation of the fiber optics position implanted into the NAc of the mice with AAV expressing EYFP (blue) and eNpHR3.0-EYFP (red). $\boldsymbol{D}$, Confocal images of NAc showing the colocalization of EYFP (green in $\boldsymbol{D}$ ) signal with dopaminergic neuron marker tyrosine hydroxylase (TH, red in $\boldsymbol{D}$ ) in NAc region after injection of AAV5-EF1a-DI0-EYFP (top) or AAV5-EF1a-DI0-eNpHR3.0-EYFP (bottom) in VTA. Scale bars: 500 $\mu$ m (B) and $10 \mu \mathrm{m}(\boldsymbol{D}) . \boldsymbol{E}$, Optogenetic inhibition of dopamine release in NAc promoted the struggling behavior during the TST. Optogenetic inhibition using yellow light was performed at $180 \mathrm{~s}$ from the onset of the TST, and terminated at $240 \mathrm{~s}$ as indicated by shading with yellow color ( $N=7$ mice for EYFP group, $N=7$ mice for eNpHR3.0 group); ${ }^{* *} p<0.01$. Two-way ANOVA followed by Sidak's post hoc test. Values are presented as the mean \pm SEM. 
during this period in the TST. Interestingly, results showed that inhibiting the dopamine release in NAc promoted the struggling behavior in mice with eNpHR3.0-EYFP compared with mice with EYFP $(p<0.01$ at $210 \mathrm{~s}$ after the onset of the TST, significant group $\times$ time interaction, $F_{(11,66)}=2.974, p=0.0031$, twoway ANOVA followed by Sidak's post hoc test; Fig. 6E). These results suggested that suppressing the dopamine release in NAc led to the struggling behavior for active stress-coping, which is consistent with reduction of dopamine in the transition from immobility to struggling.

\section{Region-specific deletion of dopamine receptors using in vivo genome editing}

Dopaminergic transmission is mediated by the family of dopamine receptors, which primarily consists of the D1 and D2 subfamilies. To examine the downstream signaling mechanisms of the released dopamine in the modulation of the behavioral transition from passive to active coping, we adopted a viral vector-mediated gene knock-out strategy using CRISPR/Cas9 targeting the Drd1a or Drd2 genes in the NAc.

First, candidate guide RNAs targeting murine Drd1a and $\operatorname{Drd} 2$ genes were screened for optimal cleavage efficiency of the genomic DNA by Cel-I assay using the genome of the N2A cell lines transfected with plasmid carrying candidate guide RNAs (Tables 1, 2 for Drd1a and Drd2 genes, respectively). We chose Drd1a\#6 and Drd2\#9 showing higher cleavage efficiency and off target score predicted in silico to generate AAV viruses harboring the saCas9 without (AAVsaCas9) or with guide RNA targeting either the first transmembrane domain of Drd1a (AAV-saCas9-Drd1sg; Table 1, hashed rows) or fourth transmembrane domain of Drd2 (AAV-saCas9-Drd2sg; Table 2, hashed rows).

Injection of these AAVs targeting the NAc of wild-type mice transduced a substantial number of ventral striatal neurons in all mice that received the AAV injection (Fig. $7 A, E, I, N, R, V$ ). Quantitative analyses for detecting the D1R protein revealed that the AAV-saCas9-Drd1sg group (NAc-D1R KO) showed a $61.4 \%$ lower D1R expression in the NAc than did the control group that was injected with AAV-saCas9 $\left(p=0.0001, F_{(2,11)}=0.868\right.$, one-way ANOVA; Fig. 7M). This effect of AAV-saCas9-Drd1sg was specific to the Drdla, since we did not observe significant D2R expression reduction in the NAc-D1R KO. Specific reduction of the gene of our interest was also achieved when we targeted the NAc by AAV-saCas9-Drd2sg (NAc-D2R KO), which showed a significant decrease in D2R expression in the NAc $\left(p<0.0001, F_{(2,10)}=0.806\right.$, one-way ANOVA; Fig. $\left.7 Z\right)$.

These results were further validated by deep sequencing of the genome edited by AAV carrying the CRISPR/Cas9 cassette. Results using next generation sequencing revealed that genomic DNA in NAc-D1R and NAc-D2R KOs, but not the control, frequently showed modification of the Drd1a (Fig. 8A) and Drd2 gene (Fig. $8 B$ ), respectively. Specifically, mutation consisted primarily of $1 \mathrm{bp}$ insertion (63.3\% and $64.1 \%$ for NAc-D1R KO and NAc-D2R KO, respectively) or deletion (36.7\% and $35.9 \%$ for NAc-D1R KO and NAc-D2R KO, respectively), both of which resulted in the generation of a premature stop codon (Fig. $8 C-E$ ). Since the antibodies used to detect D1R and D2R proteins are supposed to recognize the domains located on the carboxylterminal side of the targets (Fig. $8 D, E$ ), they are likely to fail to detect the truncated protein encoded by genes mutated by the in vivo genome editing.

Collectively, in vivo genome editing successfully knocked out the Drd1a or Drd2 genes, specifically in the NAc with high efficiency and specificity, which provided us with a valuable tool for manipulating dopaminergic signaling in the following experiments.

\section{Ablation of D1R transmission in the NAc potentiates struggling behavior in the TST}

We first checked the effect of knocking out the dopaminergic receptor in the NAc on locomotor activity. Open-field tests revealed that traveled distance of the NAc-D2R KO mice (Fig. $9 A$, red) was significantly shorter than that of both the control $\left(p=0.0405, F_{(2,34)}=2.694\right.$, one-way ANOVA; Fig. 9A, $B$, black $)$ and NAc-D1R KO $\left(F_{(2,34)}=2.694\right.$, one-way ANOVA; blue in Fig. $9 A, B)$ mice, suggesting that the locomotor activity was affected by $\mathrm{D} 2$ but not by D1 transmission in the NAc.

We next subjected the KO mice to the TST to examine the effect of dopaminergic receptor deletion on the stresscoping behavior under tail suspension. During the time course of the body movement in the mice, we observed struggling behaviors more frequently in NAc-D1R KO (Fig. 9D) mice than in the control (Fig. 9C) and NAc-D2R KO (Fig. 9E) mice. Population analysis revealed that the number of struggling bouts in NAc-D1R KO mice were significantly higher than those in the control and NAc-D2R KO mice $\left(p=0.026\right.$ and $p=0.023$, respectively, $F_{(2,29)}=0.147$, one-way ANOVA; Fig. $9 F$ ). These differences in behaviors were associated with an elongation of latency to immobility in NAc-D1R KOs $(p=0.048$ and $p=0.004$, respectively, $F_{(2,27)}=3.672$, one-way ANOVA; Fig. $\left.9 G\right)$, suggesting that the deletion of D1R function in the NAc made the mice more prone to show struggling rather than immobile behaviors. This view was further supported by the shortening of the immobility duration $(p=0.031$ and $p=0.025$, respectively, $F_{(2,26)}=0.650$, one-way ANOVA; Fig. $\left.9 H\right)$.

Taken together, behavioral analysis of the mice with conditional knock-out of D1 and D2 function in the NAc unraveled a novel role of dopaminergic transmission through D1Rs in stresscoping behaviors under tail suspension stress.

\section{Discussion}

The current study uncovered the dynamics of dopaminergic transmission during the transition of coping behaviors and provided multiple lines of evidence to support the dopamine transmission and the frequency of stress-coping behaviors. These results indicate that dopaminergic signaling through D1Rs in the NAc controls stress-coping behaviors in animals under inescapable stress. We discuss below the possible mechanisms by which dopamine modulates the coping with acute stress during the TST.

\section{Dopaminergic transmission in the brain under inescapable stress}

Immobility, also known as despair-like behavior, could be a consequence of the animal giving up its intent to escape. An alternate view is that immobility is a behavioral choice to conserve energy for later activity and to wait for the precarious situation to improve (Lyons and Schatzberg, 2020). Not only a strategic shift of coping behavior to escape or to save energy but also accumulating fatigue and fear for predation during struggling might also facilitate the immobility and struggling, respectively (Cryan et al., 2005). Examining the effects of those additional factors on dopamine metabolism will further deepen our understanding of the neural substrate for coping with stress.

Recent studies have suggested that dopaminergic transmission encodes the prediction error to reinforce the behavioral choice so 

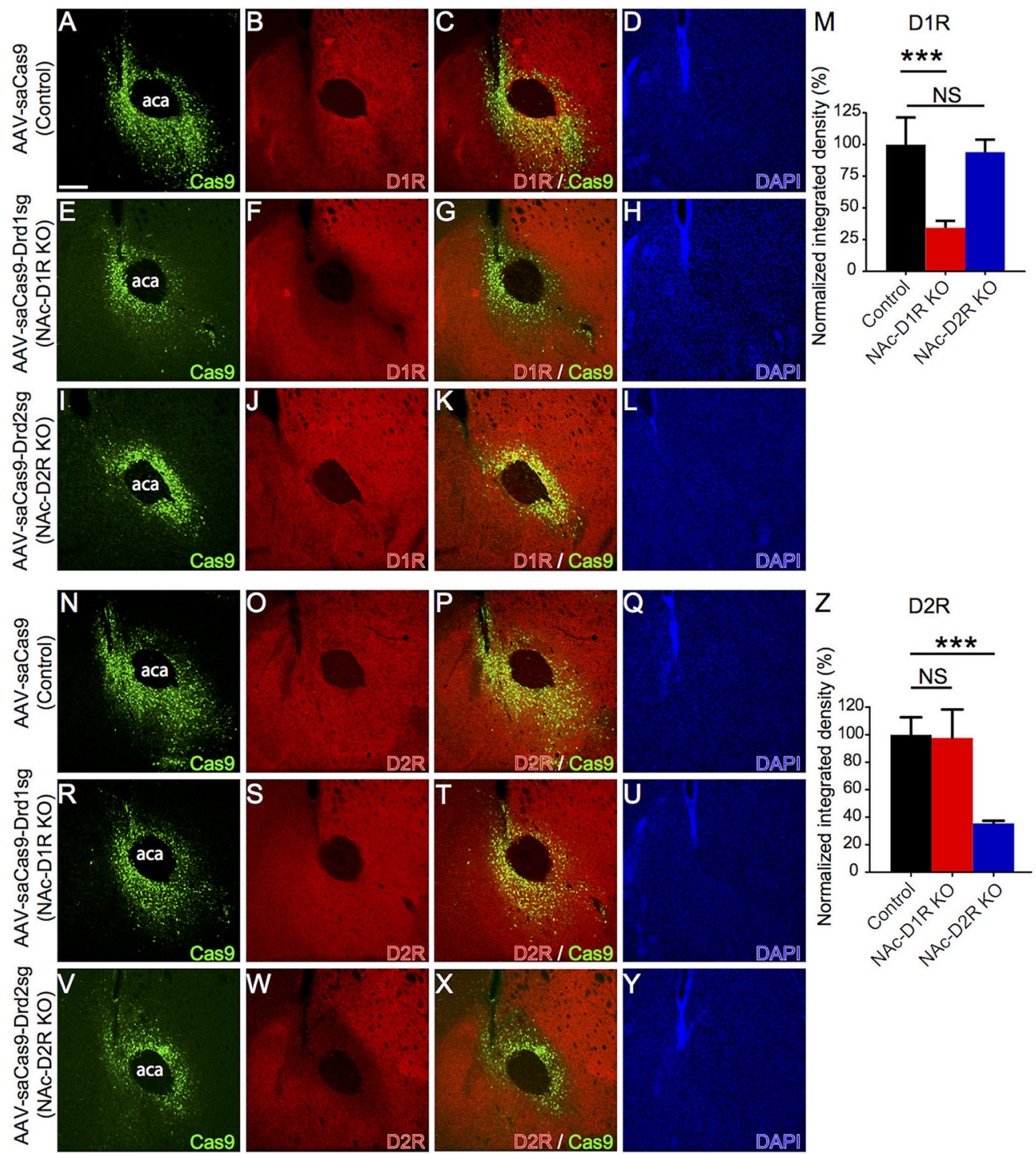

Figure 7. Viral vector-mediated gene transduction encoding Cas 9 and guide RNA specifically reduces protein expression of the type 1 and type 2 dopamine receptors in the nucleus accumbens. $A-L$, Coronal sections of NAc of mice that received injections of AAV-CRISPR/Cas9 vectors with no target [AAV-SaCas9 (control); A-D], targeting Drd1a [AAV-SaCas9-Drd1sg (NAC-D1R K0); $\boldsymbol{E}-\boldsymbol{H}$ ] and Drd2 [AAV-SaCas9-Drd2 (NAC-D2R K0); $\boldsymbol{I - L}$ ] showing HA-tagged Cas9 (green in $\boldsymbol{A}, \boldsymbol{C}, \boldsymbol{E}, \boldsymbol{G}, \boldsymbol{I}, \boldsymbol{K}$ ), D1R (red in $\boldsymbol{B}, \boldsymbol{C}, \boldsymbol{F}, \boldsymbol{G}, \boldsymbol{J}, \boldsymbol{K}$ ), and nucleus (DAPl; blue in $\boldsymbol{D}, \boldsymbol{H}, \boldsymbol{L}$ ). $\boldsymbol{M}$, Bar graph showing the normalized integrated density of the fluorescence labeling for the D1R in the NAc of the Control (black), NAc-D1R K0 (red), and NAc-D2R K0 mice (blue) expressing Cas9. $N-Y$, Coronal sections of the NAc of the mice that received injections of AAV-CRISPR/Cas9 vectors with no target [AAV-SaCas9 (control); $\mathbf{N}-\mathbf{Q}]$, targeting Drd1a [AAV-SaCas9-Drd1sg (NAc-D1R K0); $\boldsymbol{R}-\boldsymbol{U}$ ] and Drd2 [AAV-SaCas9-Drd2 (NAc-D2R K0); $\boldsymbol{V}-\boldsymbol{V}$ ] showing HA-tagged Cas9 (green in $\boldsymbol{N}, \boldsymbol{R}, \boldsymbol{V}, \boldsymbol{P}, \boldsymbol{T}, \boldsymbol{X}$ ), D2R (red in $\mathbf{O}, \mathbf{S}, \boldsymbol{W}, \boldsymbol{P}, \boldsymbol{T}, \boldsymbol{X}$ ), and nucleus (DAPl; blue in $\mathbf{Q}, \boldsymbol{U}, \boldsymbol{\eta}$ ). $\boldsymbol{Z}$, Bar graph showing the normalized integrated density of the fluorescence labeling for the D2R in the NAc of the control (black), NAc-D1R KO (red), and NAc-D2R KO mice (blue) expressing Cas9; N= 5 mice for each group, ${ }^{* * *} p<0.001$ (one-way ANOVA followed by Tukey's multiple comparison test). Scale bar: $100 \mu \mathrm{m}(\boldsymbol{A})$. NS, not significant; aca, anterior part of the anterior commissure.

that the difference between the prediction and the outcome is minimized (Matsumoto and Hikosaka, 2009; Bromberg-Martin et al., 2010). Measurements of dopamine release in the current study revealed a transient reduction of extracellular dopamine in the NAc preceding the initiation of struggling behaviors during tail suspension. This suggests that dopaminergic transmission in the NAc might be involved in initiating the body movements to cope with inescapable stress, as is assumed to occur in the tail suspension condition. Since the direction of change in dopamine concentration is opposite to that in the rewarding condition, this change might reflect the negative prediction error, which predicts a negative outcome based on learning in the environment with inescapable stress. The firing of dopaminergic neurons displays a negative modulation by effort level during the task performance of the animal, while it displays a reliable positive encoding of the reward size (Walton and Bouret, 2019). Thus, transient dopamine reduction at the onset of struggling under tail suspension might be involved with a negative prediction error for choice with presumptively high effort.

In contrast, dopamine has been implicated in the processing of aversive information such as those encoding fear and anxiety to avoid negative outcomes that threaten survival (Badrinarayan et al., 2012; Oleson et al., 2012; Wenzel et al., 2015). Recent studies have reported that distinct subtypes of dopaminergic neurons in the midbrain respond differentially to aversive stimuli to orchestrate neural information underlying the avoidance behaviors (Ungless et al., 2004; Bromberg-Martin et al., 2010; Takahashi et al., 2017). Indeed, dopamine release was shown to transiently decrease on perception of a conditioned stimulus predicting footshock (Badrinarayan et al., 2012) and on inescapable footshock (Oleson et al., 2012; Wenzel et al., 2018). Since fear and anxiety are likely to accumulate and peak at the end of the immobility period, the reduction of dopamine levels as observed 

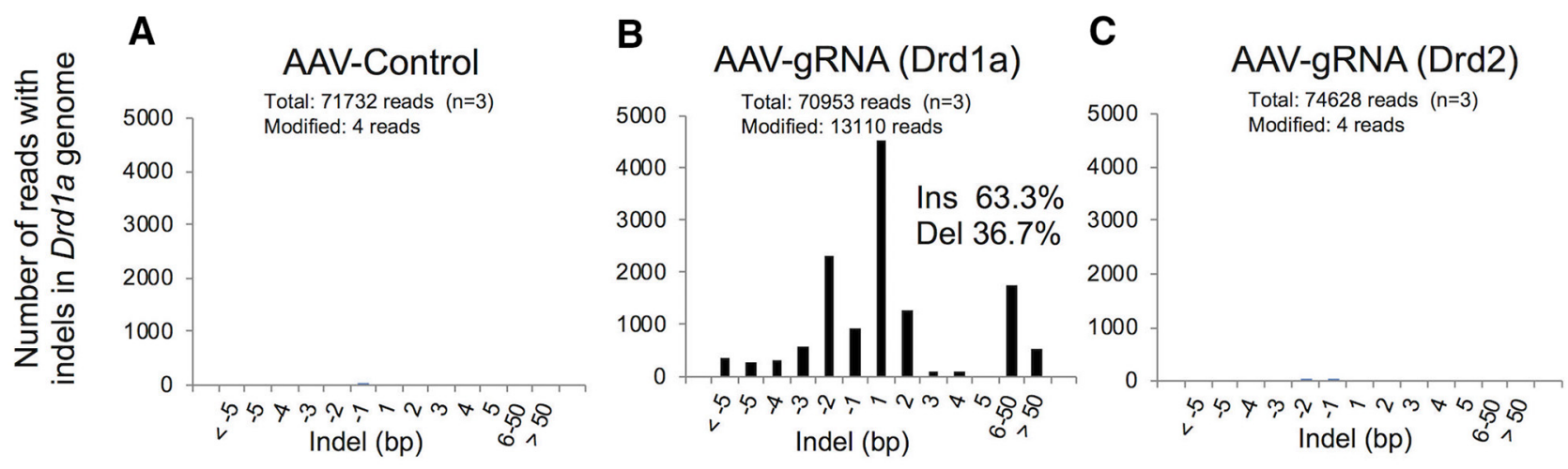
D 5'-ATCCTGTCCACTCTCTTAGGGAATACC-3'

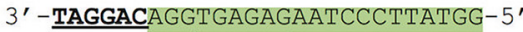 PAM guide RNA

$$
\text { DSB }
$$

F genomic DNA

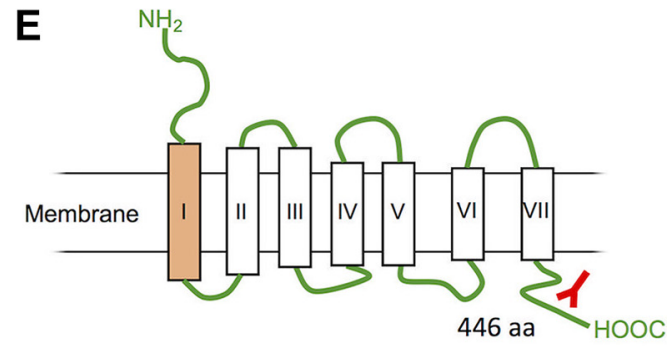

WT 5'-TTTTCTGTCCCTGCTTATCCTGTCC-ACTCTCTTAGGGAATACCT-3'

M1 5'-TTTTCTGTCCCTGCTTATCCTGTCCTACTCTCTTAGGGAATACCT-3

M2 5'-TTTTCTGTCCCTGCTTATCCTGTCCAACTCTCTTAGGGAATACCT-3'

M3 5'-TTTTCTGTCCCTGCTTATCCTGT---ACTCTCTTAGGGAATACCT-3'

M4 5 5 -TTTCTGTCCCTGCTTATCCTGTCC---TCTCTTAGGGAATACCT-3 ${ }^{\prime}$

M4 5'-TTTTCTGTCCCTGCTTATCCTGTCCCACTCTCTTAGGGAATACCT-3'

G predicted amino acids

$\begin{array}{lll}\text { WT } & \text { MAPNTSTMDETGLPVERDFSFRILTACFLSLLILSTLLGNTLVCAAVIRFRHLRSKVTNFFVISLAVSDLLVAVLVMPWKAVA... } & 446 \text { aa } \\ \text { M1 } & \text { MAPNTSTMDETGLPVERDFSFRILTACFLSLLILSYSLREYPCLCRCHQVSTPAVQGDQLLCHLFSCVRSLGGCLGHALESCGStop } & 83 \text { aa } \\ \text { M2 } & \text { MAPNTSTMDETGLPVERDFSFRILTACFLSLLILSNSLREYPCLCRCHQVSTPAVQGDQLLCHLFSCVRSLGGCLGHALESCGSTOP } & 83 \text { aa } \\ \text { M3 } & \text { MAPNTSTMDETGLPVRDFSFRILTACFLSLIILYSLREYPCLCRCHQVSTPAVQGDQLCHLFSCVRSLGCLGHALSCGSTOP } & 82 \text { aa } \\ \text { M4 } & \text { MAPNTSTMDETGLPVERDFSFRILTACFLSLLILSSLREYPCLCRCHQVSTPAVQGDQLLCHLFSCVRSLGGLGHALESGSTOP } & 82 \text { aa } \\ \text { M5 } & \text { MAPNTSTMDETGLPVERDFSFRILTACFLSLLILSHSLREYPCLCRCHQVSTPAVQGDQLLCHLFSCVRSLGGCLGHLESCGSTOP } & 83 \text { aa }\end{array}$

$A^{\prime}$

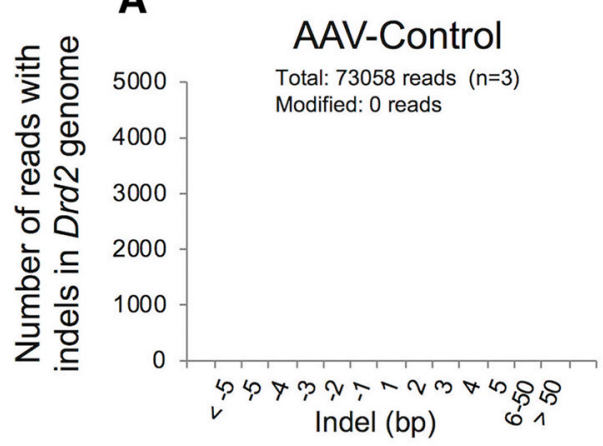

B'

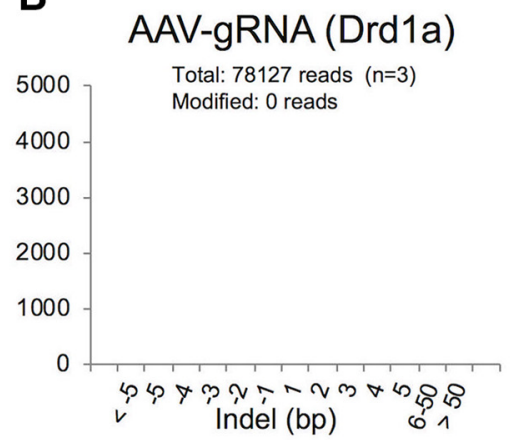

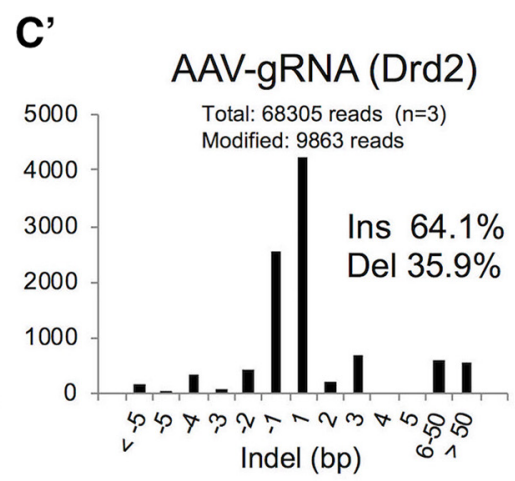

$$
\begin{aligned}
& \text { D' } \underset{\text { 5'-TACTGTCATGATCGCCATTGTCTGGGT-3, }}{\text { guide RNA }} \stackrel{\text { DSB }}{\text { PAM }} \\
& 3^{\prime} \text {-ATGACAGTACTAGCGGTAACAGACCCA-5' }
\end{aligned}
$$

F' genomic DNA

WT 5'-AAGCGCCGAGTTACTGTCATGATCGCCAT---TGTCTGGGTCCTG-3'

M1 5'-AAGCGCCGAGTTACTGTCATGATCGCCATT--TGTCTGGGTCCTG-3'

M2 5'-AAGCGCCGAGTTACTGTCATGATCGCCAT----GTCTGGGTCCTG-3'

M3 5'-AAGCGCCGAGTTACTGTCATGATCGCCATA--TGTCTGGGTCCTG-3'

M4 5' -AAGCGCCGAGTTACTGTCATGATCGCCATG--TGTCTGGGTCCTG-3'

M5 5' -AAGCGCCGAGTTACTGTCATGATCGCCATGTCTGTCTGGGTCCTG-3'

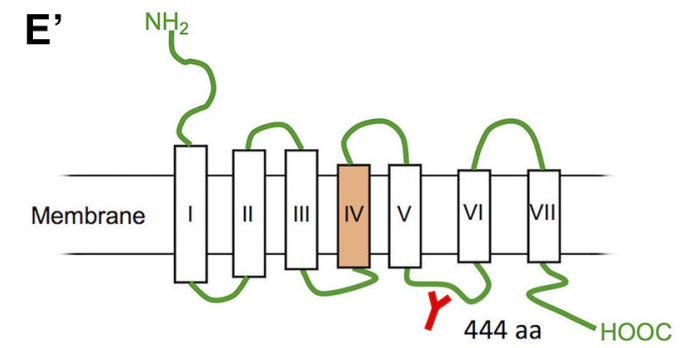

G' predicted amino acids

WT ....KRRVTVMIAI-VWVLSFTISCPLLFGLNNTDQNECI IANPAFVVYSSIVSFYVPFIVTLLVYIKIYIVLRKRRKRVNTKRSSRAFRANL . . . 444 aa

M1 ...KRRVTVMIAI-CLGPVLHHLLPTALWTQQHRPEStOP

M2 ....KRRVTVMIAM-SGSCPSPSLAHCSLDSTTQTRMSVSLPTLPSWSTPPSSRSTCPSSSPCWSISKSTSFSASVGSGSTPSVAAELSEPTS top 230 aa

M4 ...KRRVTVMIAI-CLGPVLHHLLPTALWTQQHRPES TOP

180 aa

TOP

180 aа

M5 ....KRRVTVMIAMSVWVLSFTISCPLLFGLNNTDQNECI IANPAFVVYSSIVSFYVPFIVTLLVYIKIYIVLRKRRKRVNTKRSSRAFRANL . . . 445 aa

Figure 8. Viral vector-mediated gene transduction knocked out the dopamine receptor genes by generation of a premature stop code in vivo. $A-C, A^{\prime}-C^{\prime}, B a r$ graphs showing a histogram of the frequency of indels in $\operatorname{Drd1a}(\boldsymbol{A}-\boldsymbol{C})$ and $\operatorname{Drd2}\left(\boldsymbol{A}^{\prime}-\boldsymbol{C}\right)$ genes of the control $(\boldsymbol{A}, \boldsymbol{A})$, NAc-D1R KO $(\boldsymbol{B}, \boldsymbol{B})$, and NAc-D2R K0 mice (C, C). Note that indels were observed exclusively in $\boldsymbol{B}, \boldsymbol{C}$. $\boldsymbol{D}$, $\boldsymbol{D}^{\prime}$, Partial sequences of the $\operatorname{Drd1a}(\boldsymbol{D})$ and $\operatorname{Drd} 2\left(\boldsymbol{D}^{\prime}\right)$ genes targeted by guide RNA (highlighted by green) next to the PAM where the double strand break of the genomic DNA is supposed to 

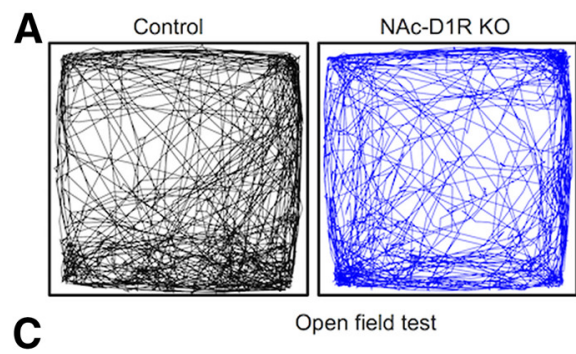

C

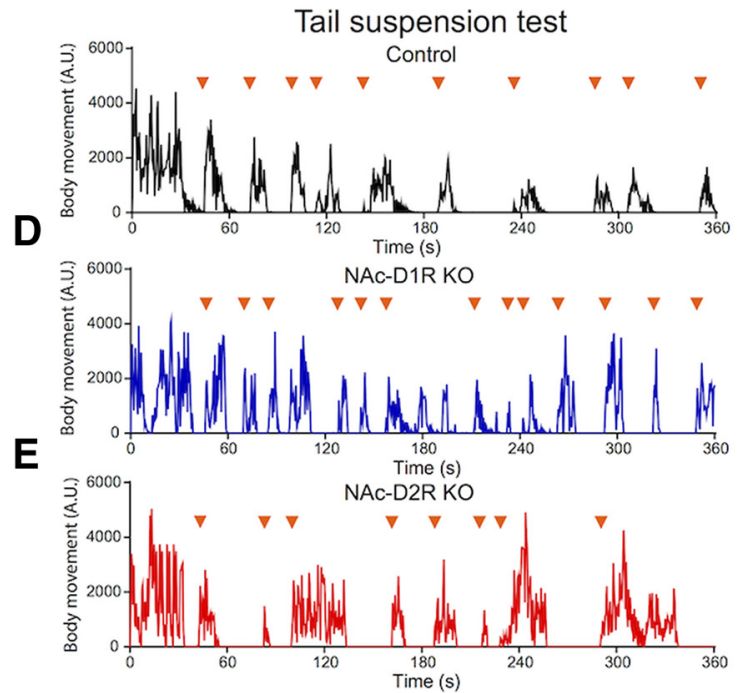

NAc-D2R KO
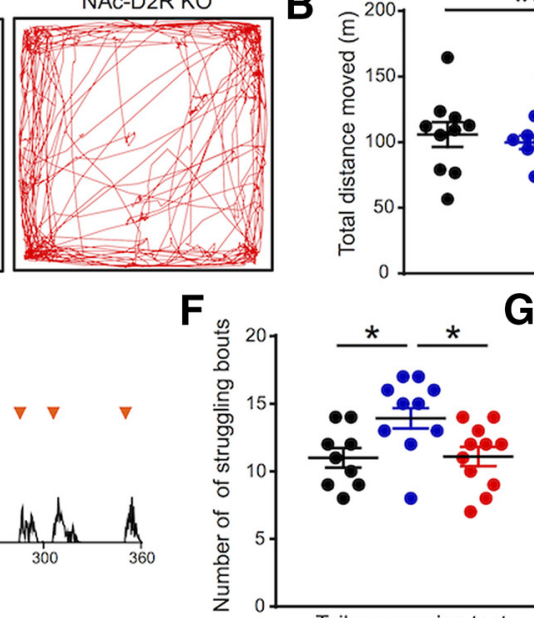

$\mathrm{H}$

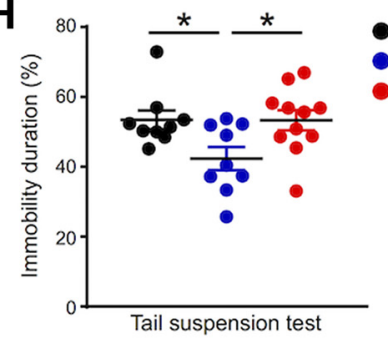

Tail suspension test

B
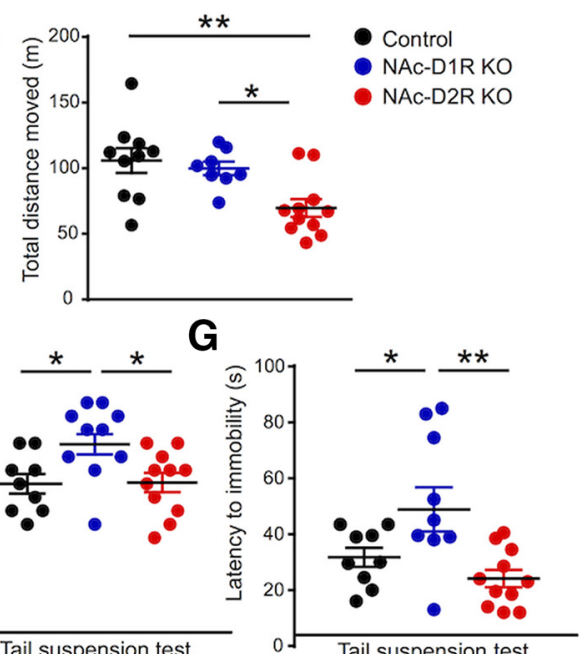

Control

NAc-D1R KO

NAc-D2R KO

Figure 9. Impaired D1 transmission resulted in frequent struggling behaviors under the TST. $\boldsymbol{A}, \boldsymbol{C}-\boldsymbol{E}$, Representative open-field traces ( $\boldsymbol{A}$ ) and time course of body movement during the TST of control $(\boldsymbol{C})$, NAc-D1R KO $(\boldsymbol{D})$, and NAc-D2R KO mice $(\boldsymbol{E})$. Arrowheads in $\boldsymbol{E}$ represent the onset of struggling bouts. $\boldsymbol{B}, \boldsymbol{F}-\boldsymbol{H}$, Dot plots showing the total distance moved in the open-field test $(\boldsymbol{B})$, the number of struggling bouts $(\boldsymbol{F})$, latency to immobility $(\boldsymbol{G})$, and immobility duration during tail suspension (H) of control (black dots), NAc-D1R K0 (blue dots), and NAc-D2R K0 (red dots) injections into the NAc ( $N=8-11$ mice, ${ }^{*} p<0.05,{ }^{* *} p<0.01$ with one-way ANOVA followed by Tukey's multiple comparison test). Values are presented as the mean \pm SEM.

in the current study might occur dependent on such an increase in aversive information.

Healthy subjects could develop resilience to stress; however, this behavioral adaptation is impaired in patients with major depressive disorder (MDD). Dysregulation of dopamine transmission in NAc may control the adaptation to stress. Since we observed a decrease of dopaminergic signaling when the animals shifted behaviors from passive (immobility) to active coping (struggling), our study provides new insight on dopamine transmission in regulation of stress coping strategy which is impaired in MDD.

Current analysis used male mice to avoid possible effect variation of the CNS function according to the estrus cycle. Indeed, it is reported that the TST is sensitive to the stage in the estrus cycle in female C57BL6/J mice (Meziane et al., 2007). Taking into consideration the fact that the prevalence of MDD is higher in women than in men (Cyranowski et al., 2000), examining female mouse under the TST would provide deeper insight into the similarities and differences of the role of dopaminergic transmission in stress coping between sexes.

$\leftarrow$

occur. $E, \boldsymbol{E}^{\prime}$, Schematics of D1R $(\boldsymbol{E})$ and D2R ( $\left.\boldsymbol{E}^{\prime}\right)$ proteins showing the transmembrane domain targeted by the guide RNA (indicted by orange, transmembrane domains I and IV for $D 1 R$ and D2R, respectively). Position of the amino acid sequences recognized by the antibodies used in immunohistochemistry are indicated by red. $\boldsymbol{F}, \boldsymbol{F}^{\prime}, \boldsymbol{G}, \boldsymbol{G}^{\prime}$, Partial genomic (top) and predicted amino acid sequences for $\operatorname{Drd} 1 a(\boldsymbol{F}, \boldsymbol{G})$ and $\operatorname{Drd} 2\left(\boldsymbol{F}^{\prime}, \boldsymbol{G}\right)$ genes of wild-type (top) and modified genome (M1 to M5) with indels (red). PAM sequences were underlined. Indels resulted in the frame shift of predicted amino acids (blue) as well as premature stop codon (red in $\mathbf{G}, \mathbf{G}$ ). Data were from $N=3$ mice for each group.
Dopamine receptor subtypes in NAc and its role in behavioral modulations

D1 and D2 receptors are two major subtypes in the dopaminergic receptors family and play critical roles in defining two distinct pathways in the dorsal striatum (Albin et al., 1989; Beaulieu and Gainetdinov, 2011). Despite their known roles in the dorsal striatum, their differential roles in the ventral striatum remains unclear, because, at least in part, they are expressed in presynaptic axonal terminals of neurons outside the NAc as well as in the dendrites and soma of the postsynaptic NAc neurons (Gerfen et al., 1990; Gerfen, 1992; Surmeier et al., 1996; De Mei et al., 2009). Results by knocking out these receptors in NAc neurons in this study clarified the role of postsynaptic dopaminergic receptors in the NAc in the stress coping behaviors.

For dopaminergic receptor genes, a germline knock-out strategy to address distinct roles of D1 and D2 have been frequently used. Although the behavioral phenotypes of mice lacking D1 and D2 receptors showed contradictory results (Kelly et al., 1998; Tran et al., 2002, 2005; McNamara et al., 2003), a recent analysis with the same genetic background demonstrated that D2 germline knock-out resulted in hypolocomotion (Nakamura et al., 2014). Our data from the open-field tests were consistent with this, further validating this strategy to analyze the dopaminergic receptor genes.

Neural pathway regulating accumbal dopamine release under the inescapable stress

Although current study revealed a role of D1R signaling in modulation of the active coping in the TST, mechanisms underlying 
how or why the dopamine release was altered during the TST remains elusive. Pathways underlying the transient inhibition of dopamine release on initiation of struggling behavior in the TST still needs further investigation.

A recent study suggested that D1 expression in medium spiny neurons (MSNs) in the lateral division of NAc (NAcLat) predominantly inhibit GABA neurons in the VTA, which disinhibits the dopamine neurons projecting back to NAcLat (Yang et al., 2018). In contrast, dopaminergic transmission is proposed to affect the activity of MSNs in the NAc, which, in turn, provides a significant inhibitory feedback innervation of the dopaminergic neurons (Beier et al., 2015).

In our study, we found that a D1R ablation in the NAc region effectively increased the active coping behavior in animals under stress, suggesting that the reduced dopamine release in the NAc region initiated an active coping behavior. Assuming that the reduction of dopamine release results from a decrease in the firing rate of a subpopulation of dopamine neurons, dopamine neurons projecting to NAcLat might further decrease their activity because of the loss of disinhibition from NAcLat-D1MSNs. Since multiple lines of evidence support the view that the connectivity of NAc and VTA are significantly shaped by conditions such as social stress (Krishnan et al., 2007; Lammel et al., 2008; Holly et al., 2016; Edwards et al., 2017), it would be interesting to test whether the reciprocal connectivity between NAc and VTA are modified in coping with inescapable stress. Examining the dopamine release by FSCV in D1R or D2R KO mice may clarify a role of interplay between NAc and VTA in the TST.

Another candidate region underlying the processing of stressrelated behavior is the lateral habenula, which receives massive innervation of dopaminergic neurons and which inhibits the activity of midbrain dopaminergic neurons via activation of GABAergic neurons in the rostromedial tegmental nucleus (Aizawa and Zhu, 2019). Since it is frequently reported that lateral habenular neurons are activated in response to aversive stimuli (Gao et al., 1996) and negative prediction error (Matsumoto and Hikosaka, 2009), enhanced aversion and negative prediction errors might result in the transient inhibition of midbrain dopaminergic neurons via this pathway.

In our study, we also observed a basic shift of $\mathrm{pH}$ in animal's transition from immobile to struggling, which suggests enhanced neural activity of neurons in NAc. Since majority of excitatory input to NAc are from the cortex, the enhanced cortical input in the transition to struggling behavior may be important for the potentiation and maintenance of the struggling behavior ( $\mathrm{Li}$ et al., 2018).

Taking the heterogeneity of the NAc afferents into consideration, to address the questions asked above, analysis using pathway-specific genetic manipulation would be one of the most promising and effective approaches (Lammel et al., 2008, 2011; Marinelli and McCutcheon, 2014). Application of these technologies to animals under tail suspension stress would deepen our understanding of the neural substrates underlying stress-coping during inescapable stress including those implicated in stress-related psychiatric disorders, such as MDD and PTSD.

\section{References}

Aida T, Chiyo K, Usami T, Ishikubo H, Imahashi R, Wada Y, Tanaka KF, Sakuma T, Yamamoto T, Tanaka K (2015) Cloning-free CRISPR/Cas system facilitates functional cassette knock-in in mice. Genome Biol 16:87.

Aizawa H, Zhu M (2019) Toward an understanding of the habenula's various roles in human depression. Psychiatry Clin Neurosci 73:607-612.
Albin RL, Young AB, Penney JB (1989) The functional anatomy of basal ganglia disorders. Trends Neurosci 12:366-375.

Bäckman CM, Malik N, Zhang Y, Shan L, Grinberg A, Hoffer BJ, Westphal $\mathrm{H}$, Tomac AC (2006) Characterization of a mouse strain expressing Cre recombinase from the 3 ' untranslated region of the dopamine transporter locus. Genesis 44:383-390.

Badrinarayan A, Wescott SA, Vander Weele CM, Saunders BT, Couturier BE, Maren S, Aragona BJ (2012) Aversive stimuli differentially modulate real-time dopamine transmission dynamics within the nucleus accumbens core and shell. J Neurosci 32:15779-15790.

Bath BD, Michael DJ, Trafton BJ, Joseph JD, Runnels PL, Wightman RM (2000) Subsecond adsorption and desorption of dopamine at carbonfiber microelectrodes. Anal Chem 72:5994-6002.

Beaulieu JM, Gainetdinov RR (2011) The physiology, signaling, and pharmacology of dopamine receptors. Pharmacol Rev 63:182-217.

Beier KT, Steinberg EE, DeLoach KE, Xie S, Miyamichi K, Schwarz L, Gao XJ, Kremer EJ, Malenka RC, Luo L (2015) Circuit architecture of VTA dopamine neurons revealed by systematic input-output mapping. Cell 162:622-634.

Berton O, McClung CA, Dileone RJ, Krishnan V, Renthal W, Russo SJ, Graham D, Tsankova NM, Bolanos CA, Rios M, Monteggia LM, Self DW, Nestler EJ (2006) Essential role of BDNF in the mesolimbic dopamine pathway in social defeat stress. Science 311:864-868.

Bromberg-Martin ES, Matsumoto M, Hikosaka O (2010) Dopamine in motivational control: rewarding, aversive, and alerting. Neuron 68:815-834.

Bucher ES, Brooks K, Verber MD, Keithley RB, Owesson-White C, Carroll S, Takmakov P, McKinney CJ, Wightman RM (2013) Flexible software platform for fast-scan cyclic voltammetry data acquisition and analysis. Anal Chem 85:10344-10353.

Chaudhury D, Walsh JJ, Friedman AK, Juarez B, Ku SM, Koo JW, Ferguson D, Tsai HC, Pomeranz L, Christoffel DJ, Nectow AR, Ekstrand M, Domingos A, Mazei-Robison MS, Mouzon E, Lobo MK, Neve RL, Friedman JM, Russo SJ, Deisseroth K, et al. (2013) Rapid regulation of depression-related behaviours by control of midbrain dopamine neurons. Nature 493:532-536.

Chesler M (2003) Regulation and modulation of $\mathrm{pH}$ in the brain. Physiol Rev 83:1183-1221.

Clark JJ, Sandberg SG, Wanat MJ, Gan JO, Horne EA, Hart AS, Akers CA, Parker JG, Willuhn I, Martinez V, Evans SB, Stella N, Phillips PE (2010) Chronic microsensors for longitudinal, subsecond dopamine detection in behaving animals. Nat Methods 7:126-129.

Cryan JF, Mombereau C, Vassout A (2005) The tail suspension test as a model for assessing antidepressant activity: review of pharmacological and genetic studies in mice. Neurosci Biobehav Rev 29:571-625.

Cyranowski JM, Frank E, Young E, Shear MK (2000) Adolescent onset of the gender difference in lifetime rates of major depression: a theoretical model. Arch Gen Psychiatry 57:21-27.

De Mei C, Ramos M, Iitaka C, Borrelli E (2009) Getting specialized: presynaptic and postsynaptic dopamine D2 receptors. Curr Opin Pharmacol 9:53-58.

Edwards NJ, Tejeda HA, Pignatelli M, Zhang S, McDevitt RA, Wu J, Bass CE, Bettler B, Morales M, Bonci A (2017) Circuit specificity in the inhibitory architecture of the VTA regulates cocaine-induced behavior. Nat Neurosci 20:438-448.

Friedman AK, Walsh JJ, Juarez B, Ku SM, Chaudhury D, Wang J, Li X, Dietz DM, Pan N, Vialou VF, Neve RL, Yue Z, Han MH (2014) Enhancing depression mechanisms in midbrain dopamine neurons achieves homeostatic resilience. Science 344:313-319.

Gao DM, Hoffman D, Benabid AL (1996) Simultaneous recording of spontaneous activities and nociceptive responses from neurons in the pars compacta of substantia nigra and in the lateral habenula. Eur J Neurosci 8:1474-1478.

Gerfen CR (1992) The neostriatal mosaic: multiple levels of compartmental organization in the basal ganglia. Annu Rev Neurosci 15:285-320.

Gerfen CR, Engber TM, Mahan LC, Susel Z, Chase TN, Monsma FJ Jr, Sibley DR (1990) D1 and D2 dopamine receptor-regulated gene expression of striatonigral and striatopallidal neurons. Science 250:1429-1432.

Hashemi P, Walsh PL, Guillot TS, Gras-Najjar J, Takmakov P, Crews FT, Wightman RM (2011) Chronically implanted, nafion-coated Ag/AgCl reference electrodes for neurochemical applications. Acs Chem Neurosci 2:658-666. 
Heien ML, Khan AS, Ariansen JL, Cheer JF, Phillips PE, Wassum KM, Wightman RM (2005) Real-time measurement of dopamine fluctuations after cocaine in the brain of behaving rats. Proc Natl Acad Sci USA 102:10023-10028.

Holly EN, Boyson CO, Montagud-Romero S, Stein DJ, Gobrogge KL, DeBold JF, Miczek KA (2016) Episodic social stress-escalated cocaine self-administration: role of phasic and tonic corticotropin releasing factor in the anterior and posterior ventral tegmental area. J Neurosci 36:4093-4105.

$\mathrm{Hu} \mathrm{H}$ (2016) Reward and aversion. Annu Rev Neurosci 39:297-324.

Kelly MA, Rubinstein M, Phillips TJ, Lessov CN, Burkhart-Kasch S, Zhang G, Bunzow JR, Fang Y, Gerhardt GA, Grandy DK, Low MJ (1998) Locomotor activity in D2 dopamine receptor-deficient mice is determined by gene dosage, genetic background, and developmental adaptations. J Neurosci 18:3470-3479.

Kim CK, Yang SJ, Pichamoorthy N, Young NP, Kauvar I, Jennings JH, Lerner TN, Berndt A, Lee SY, Ramakrishnan C, Davidson TJ, Inoue M, Bito H, Deisseroth K (2016) Simultaneous fast measurement of circuit dynamics at multiple sites across the mammalian brain. Nat Methods 13:325-328.

Krishnan V, Han MH, Graham DL, Berton O, Renthal W, Russo SJ, Laplant Q, Graham A, Lutter M, Lagace DC, Ghose S, Reister R, Tannous P, Green TA, Neve RL, Chakravarty S, Kumar A, Eisch AJ, Self DW, Lee FS, et al. (2007) Molecular adaptations underlying susceptibility and resistance to social defeat in brain reward regions. Cell 131:391-404.

Lammel S, Hetzel A, Häckel O, Jones I, Liss B, Roeper J (2008) Unique properties of mesoprefrontal neurons within a dual mesocorticolimbic dopamine system. Neuron 57:760-773.

Lammel S, Ion DI, Roeper J, Malenka RC (2011) Projection-specific modulation of dopamine neuron synapses by aversive and rewarding stimuli. Neuron 70:855-862.

Li Z, Chen Z, Fan G, Li A, Yuan J, Xu T (2018) Cell-type-specific afferent innervation of the nucleus accumbens core and shell. Front Neuroanat 12:84.

Lyons DM, Schatzberg AF (2020) Resilience as a process instead of a trait. In: Stress resilience, Chap 3 (Chen A, ed), pp 33-44. San Diego: Academic Press.

Marinelli M, McCutcheon JE (2014) Heterogeneity of dopamine neuron activity across traits and states. Neuroscience 282:176-197.

Matsumoto M, Hikosaka O (2009) Two types of dopamine neuron distinctly convey positive and negative motivational signals. Nature 459:837-841.

Matsushita T, Elliger S, Elliger C, Podsakoff G, Villarreal L, Kurtzman GJ, Iwaki Y, Colosi P (1998) Adeno-associated virus vectors can be efficiently produced without helper virus. Gene Ther 5:938-945.

McNamara FN, Clifford JJ, Tighe O, Kinsella A, Drago J, Croke DT, Waddington JL (2003) Congenic D1A dopamine receptor mutants: ethologically based resolution of behavioural topography indicates genetic background as a determinant of knockout phenotype. Neuropsychopharmacology 28:86-99.

Meziane H, Ouagazzal AM, Aubert L, Wietrzych M, Krezel W (2007) Estrous cycle effects on behavior of C57BL/6J and BALB/cByl female mice: implications for phenotyping strategies. Genes Brain Behav 6:192-200.

Nakamura T, Sato A, Kitsukawa T, Momiyama T, Yamamori T, Sasaoka T (2014) Distinct motor impairments of dopamine D1 and D2 receptor knockout mice revealed by three types of motor behavior. Front Integr Neurosci 8:56.

Narushima M, Uchigashima M, Hashimoto K, Watanabe M, Kano M (2006) Depolarization-induced suppression of inhibition mediated by endocannabinoids at synapses from fast-spiking interneurons to medium spiny neurons in the striatum. Eur J Neurosci 24:2246-2252.

Nestler EJ, Carlezon WA Jr (2006) The mesolimbic dopamine reward circuit in depression. Biol Psychiatry 59:1151-1159.

Okada T, Nomoto T, Yoshioka T, Nonaka-Sarukawa M, Ito T, Ogura T, Iwata-Okada M, Uchibori R, Shimazaki K, Mizukami H, Kume A, Ozawa $\mathrm{K}$ (2005) Large-scale production of recombinant viruses by use of a large culture vessel with active gassing. Hum Gene Ther 16:1212-1218.
Oleson EB, Gentry RN, Chioma VC, Cheer JF (2012) Subsecond dopamine release in the nucleus accumbens predicts conditioned punishment and its successful avoidance. J Neurosci 32:14804-14808.

Ortiz J, Fitzgerald LW, Lane S, Terwilliger R, Nestler EJ (1996) Biochemical adaptations in the mesolimbic dopamine system in response to repeated stress. Neuropsychopharmacology 14:443-452.

Pultorak KJ, Schelp SA, Isaacs DP, Krzystyniak G, Oleson EB (2018) A transient dopamine signal represents avoidance value and causally influences the demand to avoid. eNeuro 5:ENEURO.0058-18.2018.

Roitman MF, Wheeler RA, Wightman RM, Carelli RM (2008) Real-time chemical responses in the nucleus accumbens differentiate rewarding and aversive stimuli. Nat Neurosci 11:1376-1377.

Schneider CA, Rasband WS, Eliceiri KW (2012) NIH Image to ImageJ: 25 years of image analysis. Nat Methods 9:671-675.

Segal ZV, Shaw BF, Vella DD, Katz R (1992) Cognitive and life stress predictors of relapse in remitted unipolar depressed patients: test of the congruency hypothesis. J Abnorm Psychol 101:26-36.

Steru L, Chermat R, Thierry B, Simon P (1985) The tail suspension test: a new method for screening antidepressants in mice. Psychopharmacology (Berl) 85:367-370

Surmeier DJ, Song WJ, Yan Z (1996) Coordinated expression of dopamine receptors in neostriatal medium spiny neurons. J Neurosci 16:6579-6591.

Takahashi YK, Batchelor HM, Liu B, Khanna A, Morales M, Schoenbaum G (2017) Dopamine neurons respond to errors in the prediction of sensory features of expected rewards. Neuron 95:1395-1405.e3.

Takmakov P, McKinney CJ, Carelli RM, Wightman RM (2011) Instrumentation for fast-scan cyclic voltammetry combined with electrophysiology for behavioral experiments in freely moving animals. Rev Sci Instrum 82:074302.

Tran AH, Tamura R, Uwano T, Kobayashi T, Katsuki M, Matsumoto G, Ono $\mathrm{T}$ (2002) Altered accumbens neural response to prediction of reward associated with place in dopamine D2 receptor knockout mice. Proc Natl Acad Sci USA 99:8986-8991.

Tran AH, Tamura R, Uwano T, Kobayashi T, Katsuki M, Ono T (2005) Dopamine D1 receptors involved in locomotor activity and accumbens neural responses to prediction of reward associated with place. Proc Natl Acad Sci USA 102:2117-2122.

Tye KM, Mirzabekov JJ, Warden MR, Ferenczi EA, Tsai HC, Finkelstein J, Kim SY, Adhikari A, Thompson KR, Andalman AS, Gunaydin LA, Witten IB, Deisseroth K (2013) Dopamine neurons modulate neural encoding and expression of depression-related behaviour. Nature 493:537-541.

Uchigashima M, Narushima M, Fukaya M, Katona I, Kano M, Watanabe M (2007) Subcellular arrangement of molecules for 2-arachidonoyl-glycerol-mediated retrograde signaling and its physiological contribution to synaptic modulation in the striatum. J Neurosci 27:3663-3676.

Ungless MA, Magill PJ, Bolam JP (2004) Uniform inhibition of dopamine neurons in the ventral tegmental area by aversive stimuli. Science 303:2040-2042.

Venton BJ, Michael DJ, Wightman RM (2003) Correlation of local changes in extracellular oxygen and $\mathrm{pH}$ that accompany dopaminergic terminal activity in the rat caudate-putamen. J Neurochem 84:373-381.

Walton ME, Bouret S (2019) What is the relationship between dopamine and effort? Trends Neurosci 42:79-91.

Wenzel JM, Rauscher NA, Cheer JF, Oleson EB (2015) A role for phasic dopamine release within the nucleus accumbens in encoding aversion: a review of the neurochemical literature. Acs Chem Neurosci 6:16-26.

Wenzel JM, Oleson EB, Gove WN, Cole AB, Gyawali U, Dantrassy HM, Bluett RJ, Dryanovski DI, Stuber GD, Deisseroth K, Mathur BN, Patel S, Lupica CR, Cheer JF (2018) Phasic dopamine signals in the nucleus accumbens that cause active avoidance require endocannabinoid mobilization in the midbrain. Curr Biol 28:1392-1404.e5.

Yang H, de Jong JW, Tak Y, Peck J, Bateup HS, Lammel S (2018) Nucleus accumbens subnuclei regulate motivated behavior via direct inhibition and disinhibition of VTA dopamine subpopulations. Neuron 97:434-449.e4. 